\title{
Hacia una Caracterización Lingüística de las Interacciones en WhatsApp
}

\author{
Marina Silva Alcántara* \\ Universitat Rovira i Virgili, Tarragona, Spain
}

\begin{abstract}
The emergence of new communicative contexts and new forms of interaction has led to changes in the ways of communicating. Some authors speak of a new communicative paradigm caused by a new level of interaction arisen in the technological context. In this article, we focus on a new technology that can be included in the so-called computer mediated communication: WhatsApp. The aim of this work is to study WhatsApp interactions understood as a particular type of computer-mediated talks. Specifically we will: 1) Characterize the language used in WhatsApp interactions at every linguistic level, from phonetics to pragmatics, through morphology, vocabulary and syntax. 2) Analyze how the absence of nonverbal communication (paralanguage and kinesics) in such interactions is managed. 3) Determine whether WhatsApp interactions are manifestations of spoken or written language, or, on the contrary, they are a new type of language that cannot be classified as oral or written. And 4) determine whether WhatsApp interactions can be qualified as conversational.
\end{abstract}

Keywords: Electronically mediated communication, WhatsApp, computer mediated language.

\footnotetext{
* Author's address:

Departament de Filologies Romàniques

Universitat Rovira i Virgili

Av. Catalunya 35, 43002 Tarragona, Spain

E-mail marina.sa7@hotmail.com
} 
Resumen. La aparición de nuevos contextos comunicativos y de nuevas formas de interacción ha propiciado cambios en las formas de comunicarse. Algunos autores hablan de un nuevo paradigma comunicativo provocado por un nuevo ámbito de interacción surgido en el contexto tecnológico. En este artículo, nos centramos en una nueva tecnología que puede incluirse en la denominada comunicación mediatizada por ordenador: WhatsApp. El objetivo de este trabajo es realizar un estudio de las interacciones en WhatsApp entendidas como un tipo particular de conversaciones mediatizadas por ordenador. En concreto nos proponemos: 1) Caracterizar el lenguaje utilizado en las interacciones en WhatsApp en todos los niveles de la lengua, desde la fonética hasta la pragmática, pasando por la morfología, el léxico y la sintaxis. 2) Analizar cómo se gestiona la ausencia de comunicación no verbal (paralenguaje y kinésica) en este tipo de interacciones. 3) Determinar si las interacciones en WhatsApp son manifestaciones de lenguaje oral o de lenguaje escrito. $\mathrm{O}$, si por el contrario, constituyen un nuevo tipo de lenguaje que no puede calificarse ni de oral ni de escrito. Y 4) determinar si las interacciones comunicativas en WhatsApp pueden calificarse como conversacionales.

Palabras clave: Comunicación mediatizada electrónicamente, WhatsApp, lenguaje de la red.

\section{Introducción}

La profunda transformación de las tecnologías de la información y la comunicación en los últimos años ha dado lugar a importantes cambios sociales y culturales, sobre todo en el ámbito de la comunicación y la información. La aparición de nuevos contextos y recursos comunicativos y de nuevas formas de interacción ha propiciado cambios en las formas de comunicarse. Algunos autores hablan de un nuevo paradigma comunicativo, de nuevos códigos y formas de comunicación provocados por un nuevo ámbito de interacción surgido en el contexto tecnológico en el que nos movemos en la actualidad.

Cuando nos comunicamos a través de dispositivos en red, estamos condicionados por factores determinantes como la limitación de espacio para escribir y la necesidad de fluidez y rapidez. Esto hace necesaria una nueva técnica para comunicarse con los demás. La forma tradicional de comunicación resulta demasiado lenta y extensa y no parece práctica en estos nuevos contextos.

La necesidad de nuevas técnicas de comunicación ha provocado el desarrollo de estrategias lingüísticas innovativas que tienen como objetivo crear un registro lingüístico adecuado y adaptado a las limitaciones del medio. Se 
trata de una nueva manera de comunicarnos con características específicas que la distinguen de las formas tradicionales. Como afirman Moral y García:

La Red, como nuevo medio de comunicación que está facilitando la interacción social, presenta una serie de características que le son específicas, y que hacen que la interacción y la comunicación sean distintas a las de la vida cotidiana. Así, entre la comunicación tradicional (cara a cara) y la comunicación que se desarrolla a través del ordenador (principalmente de tipo textual), pueden establecerse fundamentalmente cuatro características diferenciales: anonimato, el distanciamiento físico, el tiempo y la ausencia de comunicación no verbal (Moral \& García 2003: 134).

Muchos son los autores que consideran que estamos ante una nueva manera de comunicarnos. Para Crystal (2006) todas las formas de tecnología de internet suponen una innovación lingüística. Para este lingüista estamos ante algo completamente nuevo que no es escritura oral ni discurso escrito: estamos ante el cuarto medio, lo que él llama "computer mediated language", que viene a añadirse al lenguaje oral, al escrito y al de signos. El lenguaje utilizado en este nuevo contexto no constituye en modo alguno una amenaza para las variedades existentes. El lenguaje de la red es simplemente una nueva variedad, una nueva manera de comunicarse.

No hay acuerdo en la bibliografía en lo que respecta a la denominación de nuevo medio del lenguaje. Se ha utilizado con frecuencia la etiqueta de comunicación mediatizada por ordenador (CMC: Computer mediated communication). En ocasiones, y debido a la difusión de los mensajes de texto (SMS) y otras formas de comunicación mediante teléfonos móviles, se ha preferido una designación más general como comunicación mediatizada electrónicamente (EMC: Electronically mediated communication). Otras designaciones frecuentes en la bibliografía son netspeak (lenguaje de la red) y textspeak (lenguaje de los SMS).

Independientemente de la etiqueta que se le asigne, está claro que estamos ante una nueva manera de comunicarse y el lingüista debe ocuparse de su caracterización:

Computer mediated communication is taking over in many areas, and whether we welcome or deplore this development, it is certainly 
not reversible. It is to be expected that in this case, as in every other one, the means of communication will influence the communication itself. Just as we are compelled to give more minimal verbal responses when talking over the telephone, because our non-verbal feedback cannot be perceived, we must therefore adapt our signals and signs to the communicative possibilities a computer offers to us. It should be interesting to see, therefore, whether and if so, in which ways this kind of communication is different from others (Hentschel 1998).

Además de los géneros tradicionales, las nuevas posibilidades que abre la informática han hecho que se desarrollasen modos de comunicación ligados al empleo de las nuevas tecnologías, que han supuesto, en cierta medida, la redefinición de algunos conceptos ligados al medio de transmisión. Los mensajes de correo electrónico, los mensajes a móviles y los mensajes instantáneos (chat) se han configurado en poco tiempo como subgéneros con sus propias características estereotípicas. Una teoría general sobre la comunicación debe darles, como es lógico, cabida (Escandell 2005: 111).

Como afirma Ávila (2007), Internet puede considerarse el paradigma de la comunicación mundial y personal y "es tal su importancia y trascendencia que justifica sobradamente la necesidad de estudiar el español que allí se emplea".

La comunicación mediatizada electrónicamente o por ordenador incluye diversos tipos de tecnologías que van desde el correo electrónico a las redes sociales, pasando por los mensajes SMS, los chats o los foros de debate. Es posible encontrar abundante bibliografía dedicada a la caracterización lingüística de las interacciones en los chats y en los foros de debate. Asimismo, las repercusiones sociales de aplicaciones como Facebook, Twitter o Twenti han sido ampliamente analizadas. En este trabajo, nos centramos en una nueva tecnología que puede incluirse en la denominada comunicación mediatizada electrónicamente y cuyo análisis no ha sido abordado en profundidad todavía: WhatsApp.

WhatsApp fue creado por la empresa de Jan Koum. Es una aplicación de mensajería instantánea que permite enviar y recibir mensajes a través de Internet. Se instala de forma gratuita en el teléfono móvil y permite -además de enviar mensajes de texto- mantener conversaciones múltiples y conversaciones grupales. La aplicación permite además enviar imágenes, archivos y 
audio. Está disponible en treinta y dos lenguas, entre las que se incluye el español.

El carácter gratuito de la aplicación ha hecho que sean muchos los usuarios que utilizan esta plataforma en sus conversaciones cotidianas sustituyendo a los tradicionales SMS y a las conversaciones telefónicas. El uso masivo de estas interacciones, el que los usuarios de WhatsApp estén constantemente conversando a través de la aplicación y adaptando su lenguaje a las limitaciones del medio justifica el interés del lingüista por el tipo de lenguaje utilizado. La escasez de bibliografía sobre el tema y las características que necesariamente distinguen al lenguaje utilizado en WhatsApp del utilizado en otras aplicaciones justifican la necesidad de trabajos como el que presentamos aquí.

El objetivo de nuestro trabajo es realizar un estudio de las interacciones en WhatsApp - a partir de un corpus de datos recopilado- entendidas como un tipo particular de conversaciones mediatizadas por ordenador. En concreto nos proponemos: 1) Caracterizar el lenguaje utilizado en las interacciones en WhatsApp en todos los niveles de la lengua, desde la fonética hasta la pragmática, pasando por la morfología, el léxico y la sintaxis. 2) Analizar cómo se gestiona la ausencia de comunicación no verbal (paralenguaje y kinésica) en este tipo de interacciones. 3) Determinar si las interacciones en WhatsApp son manifestaciones de lenguaje oral o de lenguaje escrito. O, si por el contrario, constituyen un nuevo tipo de lenguaje que no puede calificarse ni de oral ni de escrito. Y 4) determinar si las interacciones comunicativas en WhatsApp pueden calificarse como conversacionales.

Respecto al corpus de datos recopilado, teniendo en cuenta que no hay un repositorio público al que acudir para obtener interacciones en WhatsApp, hemos recogido datos de personas cercanas a nosotros que amablemente se han ofrecido a poner a nuestra disposición sus interacciones a través de esta aplicación. Teniendo en cuenta que nuestro análisis no pretende ser cuantitativo, el número de conversaciones registradas no es relevante.

Este artículo está estructurado de la siguiente manera. El apartado 2 está dedicado a una de las características que más han llamado la atención de los estudiosos de este tipo de interacciones, a saber, la representación gráfica de los fenómenos propios de la lengua oral. El apartado 3 se centra en la morfología, analizando el aspecto más representativo de las interacciones en WhatsApp en lo que a morfología se refiere: uso de procesos de abreviatura y acortamiento motivados por la necesidad de agilizar el proceso de escritura 
y obtener una interacción rápida y fluida. El apartado 4 analiza los aspectos sintácticos de las interacciones en WhatsApp, con especial atención a la tipología oracional utilizada, a los procesos de elisión y de alteración del orden de palabras, a las categorías gramaticales más frecuentes y a las funciones lingüísticas que predominan en estas interacciones. El apartado 5 se dedica al estudio del léxico en las interacciones en WhatsApp, destacando la importancia de la iconicidad, el abundante uso de onomatopeyas e interjecciones, y el uso de un tipo de léxico particular en el que abundan los anglicismos y los coloquialismos. El apartado 6 se ocupa de los aspectos pragmáticos de estas interacciones, con especial atención al análisis de las características propias de las conversaciones cara a cara. El apartado 7 analiza las consecuencias de la ausencia de comunicación no verbal, ocupándose de las estrategias básicas utilizadas en las interacciones en WhatsApp para compensar la ausencia de los elementos paralingüísticos y kinésicos presentes en la conversación cara a cara. Finalmente, en el apartado 8, resumimos las principales conclusiones a las que hemos llegado con nuestro análisis y presentamos algunas líneas de investigación futura.

\section{Fonética/Ortografía: El Reflejo de lo Oral en lo Escrito}

Son muchos los autores que han puesto de manifiesto el carácter oral de la comunicación mediatizada por ordenador. Se habla de texto escrito oralizado y son muchos los que afirman que uno de los rasgos principales de este lenguaje es que los participantes escriben como hablan. Por ello, en numerosos trabajos se ha señalado que la ortografía es uno de los aspectos más interesantes en este tipo de interacciones, ya que a través de ella puede apreciarse de manera clara el carácter oralizante de estas conversaciones escritas. Podemos afirmar, por tanto, que las formas escritas en WhatsApp reflejan los fenómenos propios de la lengua oral:

Podemos hablar de aspectos fonéticos de la lengua hablada que encuentran su traducción en el uso de determinadas grafías que constituyen, en ciertos casos, una auténtica 'transcripción fonética'. [...] Es posible, pues, a partir de las formas fonéticas que aparecen en la lengua de los chats, detectar algunas características fonéticas del registro coloquial y obtener información sobre el modo en que los hablantes ponen de manifiesto mediante la escritura las formas en principio restringidas a la oralidad (Llisterri 2002: 63). 
Es necesario mencionar que muchas veces lo escrito corresponde esencialmente con una transcripción fonética (Álvarez 2011: 3).

Según Yus (2001), estos cambios y deformaciones textuales que afectan al texto escrito se producen en la mayoría de las ocasiones "como consecuencia del desfase temporal entre la rapidez e inmediatez del habla y el lento proceso de composición del texto escrito sobre la pantalla" (Yus 2001: 139).

En este apartado analizaremos los cambios, las deformaciones y, en general, los recursos utilizados por los usuarios de WhatsApp para dar a su texto escrito el carácter oralizante que caracteriza a las conversaciones mediatizadas por ordenador. Para ello utilizaremos las clasificaciones propuestas por Yus (2001) y Llisterri (2002).

Yus (2001) establece la siguiente clasificación de las alteraciones gráficas que se producen como estrategias de oralización del texto escrito:

1. (Orto)grafía fonética: "consiste en plasmar textualmente el discurso tal y como sería pronunciado de forma oral" (Yus 2001: 142).

2. (Orto)grafía coloquial: "reducción coloquial de las palabras debido a su pronunciación en la cadena hablada" (Yus 2001: 143).

3. Orto(grafía) regiolectal: "representaciones típicas de variaciones regionales de una lengua" (Yus 2001: 143).

4. Orto(grafía) prosódica: "representación de patrones prosódicos de la voz recurriendo a repeticiones de letras, uso de mayúsculas y otros signos de puntuación" (Yus 2001: 143).

5. Orto(grafía) interlingüística: "se trata de plasmar la grafía fonética de préstamos de otras lenguas pero haciéndolas pasar por el tamiz de la idiosincrasia ortográfica de la lengua de destino" (Yus 2001: 143).

6. Orto(grafía) homofónica: Incluye dos tipos de alteraciones fonéticas:

a) Sustituciones léxicas: "la estrategia de escribir alguna palabra cuya pronunciación es igual o similar a la pretendida pero que, debido a su menor longitud, se adecua mejor a la exigencia de rapidez" (Yus 2001: 144).

b) Sustituciones grafémicas: "sustituir una grafía por otra" (Yus 2001: 144).

Siguiendo a Llisterri (2002), podemos agrupar los fenómenos fonéticos que se reflejan en la ortografía en tres grandes grupos: 
1. Elisiones: omisiones de elementos grafemáticos.

2. Epéntesis: adición de elementos que no son propios de la forma normativa.

3. Substituciones: cambios de un elemento por otro.

Dentro de las elisiones podemos distinguir tres tipos diferentes dependiendo del lugar de la palabra en el que se realice la omisión del elemento:

1. Aféresis: proceso que elimina uno o más segmentos a principio de palabra.

2. Síncopa: proceso que elimina uno o más segmentos en interior de palabra.

3. Apócope: proceso que elimina uno o más segmentos en final de palabra.

En la adición de elementos se distinguen, asimismo, tres grandes tipos:

1. Prótesis: proceso que inserta uno o más segmentos en posición inicial de palabra.

2. Epéntesis: proceso que inserta uno o más segmentos en el interior de la palabra.

3. Paragoge: proceso que inserta uno o más segmentos en final de la palabra.

\section{1 (Orto)grafía Fonética}

Como hemos dicho en el apartado anterior, entendemos por ortografía fonética aquella que consiste en escribir el texto como sería pronunciado. En el caso de la ortografía fonética, predominan en WhatsApp los fenómenos de elisión y sustitución y son prácticamente inexistentes los casos de adición de material fonético.

Entre los fenómenos de ortografía fonética por elisión destaca, la omisión de la $h$ inicial. Este recurso es un claro ejemplo de ortografía fonética, en una escritura que tiende a imitar la pronunciación, no hay lugar para la grafía $h$ :

A- ya ems cenao.

A- q guay q pena q yo no e podido ir.

La grafía $h$ se elimina no solo en posición inicial de palabra, sino también en posición interior, como muestra el siguiente ejemplo:

L- aora cuando venga. 
Entre los ejemplos de ortografía fonética por substitución, destacamos el uso frecuente de la forma imeil por email así como la adaptación al español de la palabra inglesa please a través de la forma plis:

C- mandame l correo ya plis q me voy.

\section{2 (Orto) grafía Coloquial}

Por ortografía coloquial entendemos la reducción de determinados elementos debido a su pronunciación en la cadena hablada. Los fenómenos que se incluyen en este apartado son, por definición, fenómenos de elisión.

Ejemplos de fenómenos de ortografía coloquial por elisión son las formas mancontao y menterao de los siguientes ejemplos. En ellos se prescinde del auxiliar y se reducen las formas del pronombre.

mancontao la movida de ayer.

yo menterao ahora.

\subsection{Orto(grafía) Regiolectal}

En las conversaciones en WhatsApp, los usuarios intentan plasmar en el texto escrito características propias de su dialecto. Hablamos, aquí, de ortografía regiolectal. En este caso las estrategias de oralización pueden ser por omisión, adición o substitución de elementos. No obstante, la búsqueda de la rapidez en este tipo de lenguaje hace que predomine la tendencia a ahorrar tiempo y, por ello, los fenómenos que se producen con más frecuencia son los de elisión y sustitución. Pocos son los casos de adición de fonemas en los rasgos dialectales.

Ejemplos de ortografía regiolectal por elisión son los siguientes:

1. Síncopa de la consonante $d$ en posición intervocálica:

$C$ - nada no e consegio ablarle ajaj.

P- Enserio... sino yo soy la primera q no hubiera organizao na.

A-jajaja y eres tu qien lo ha recordao.

2. Frecuentemente se produce la elisión de la $d$ en la palabra joder que aparece como jue, joee:

$C$ - no puedo venir cari lo sientoo. $M$ - jueer $x q$ ?? 
3. Otro rasgo común en estas interacciones es la apócope de consonantes finales cuando van precedidas de vocal tónica: Madri (d), Interne $(t)$ :

$M$ - $l$ viernes $m$ voy a madrI.

4. Aféresis y apócope en la forma entonces:

$L$ - ntnce $k$ ?

5. Aféresis en la forma donde que aparece como onde y en la forma estás que aparece como tas:

$C$ - onde tas?

F- dnd tas?

6. Aféresis en la palabra gracias que aparece como asias:

F- qieres q $t$ pase a buscar?

M-no asias ya $m$ acerca ella a casa

Ejemplos de ortografía regional por adición son los siguientes:

1. Epéntesis de $s$ en las palabras dime y fino que aparecen como disme y fisno, respectivamente:

\section{A-Laury}

$L$ - disme.

2. Paragoge de elementos a modo de sufijos en el caso de los países latinoamericanos:

L- aiiz mi papito.

3. Paragoge de $s$ en palabras que no admiten flexión de número. Se produce sobre todo en los saludos Hola y Adiós con las formas (h)olas y adioses. Suele indicar un saludo dirigido a más de un destinatario:

A- Olas a todos.

4. Por último, encontramos paragoge de $s$ en la segunda persona del singular del pretérito indefinido de algunos verbos como hacer, haber, tener, etc.: comistes, hicistes:

$C$ - ayer $q$ hicistes?

$M$ - na $n$ estuve $n$ csa. 
Ejemplos de ortografía regional por substitución de un elemento por otro son los siguientes:

1. Encontramos casos de seseo en los que se sustituye la $c$ por la sibilante $s$ :

L- q asee?

F- qieres q $t$ pase a buscar?

M-no asias ya $m$ acerca ella a casa.

2. Otro fenómeno habitual es la sustitución de $r$ por $l$ y viceversa:

L-no zee dime argooo!!

F- bns nxes mi amol.

3. Aspiración de la $s$ en posición implosiva al final de palabra:

P- hay q ver como somoh eh.

4. Es habitual, como indica Pano (2008: 8), encontrar un "uso arbitrario de grafemas ' $\mathrm{z}$ ' y 's' correspondientes a $[s],[\theta e],[\theta] \mathrm{y}[\theta i]$ : Esto puede deberse a simples errores ortográficos, a la transgresión en la imitación del habla":

$L$ - $k$ azemo?

5. Sustitución del diptongo ue en pues por o:

M- bno ya ablms.

C-ok. Ta mañana ya $k$ ta dao pos kedams.

\subsection{Orto(grafia) Prosódica}

Los casos de ortografía prosódica, esto es la representación escrita de patrones prosódicos de la voz, se realiza a través de procesos de adición o substitución. No se documentan en este bloque casos de elisión. Lo habitual es recurrir a la repetición de letras, uso de mayúsculas y otros signos de puntuación para compensar la ausencia de canal auditivo.

El caso más claro de ortografía prosódica por adición es la reduplicación de fonemas -en la mayoría de los casos vocálicos- para dar énfasis y reproducir el tono en el texto escrito:

$N$ - dioooos eres una makina!

C-graaaciiiiaaaas chicaaas!

C-Chicaaaas me han puesto un 9.10 en las practicaaaaaas!!

l- oleeeee enhorabuenaaaa.

M- cmo va lo de l beca? P-FATAAAAL!! Me l an denegao! 
En los casos de ortografía prosódica por sustitución destacamos la sustitución de minúsculas por mayúsculas para indicar cualidades como el grito. En ocasiones, se marca en mayúscula todo un sintagma, sin embargo lo habitual es que se utilicen las mayúsculas para resaltar determinadas palabras a las que el emisor quiere dar más énfasis:

$$
\begin{aligned}
& M \text { - T DIXO Q NOOO! } \\
& C \text { - } q \text { dices q FUERTEE! }
\end{aligned}
$$

\subsection{Orto(grafía) interlingüística}

No son muy frecuentes los casos de ortografía interlingüística, esto es, aquellos que reflejan la grafía fonética de préstamos a través de las convenciones de la lengua de destino. El ejemplo más habitual es el de la forma estándar por standard.

\subsection{Orto(grafía) homofónica}

Los casos de ortografía homofónica se limitan a fenómenos de substitución, ya sea léxica o grafémica, siendo imposibles los fenómenos de elisión y adición.

En todos los casos, la ortografía homofónica responde a la habitual presión temporal que lleva al usuario de WhatsApp a querer teclear sus textos en el menor tiempo posible y, por tanto, con el menor número de pulsaciones.

Los casos de substitución léxica son aquellos en los que se recurre a escribir una palabra cuya pronunciación es igual o similar a la que se quiere realmente usar pero cuya longitud es menor y, por tanto, se adecua más a la exigencia de rapidez de estas interacciones.

Este tipo de substituciones son muy frecuentes en inglés, pero no en español. Ejemplos como every1 por everyone, l8ter por later o $c$ u l8ter por see you later son frecuentes en las interacciones en inglés.

En las conversaciones analizadas no hemos encontrado ejemplos de substituciones léxicas en español.

Las substituciones grafémicas, esto es la substitución de una grafía por otra, sí que son frecuentes en las interacciones en WhatsApp que hemos analizado. Destacan los siguientes fenómenos: 
1. Sustitución de $c$ y $q$ por $k$ :

A- yo $n$ me qiero qdar en ksa $x d$.

2. Sustitución de $l l$ por $y$ :

$M$ - me e olvidao las yaves $n$ csa.

3. Sustitución de los grupos fonemáticos gue, gua y bue por w:

A- wenas una pronta puedes psarme ls apuntes de siglos.

$M$ - un bso wapaa!

4. Sustitución de la preposición por por el signo de multiplicar $x$.

5. Sustitución frecuente del dígrafo $c h$ por $x$ :

A-lo as exo tu?

F- buenas noxes.

6. Sustitución de las formas $d e, t e, m e$ por las grafías $d, t, m$, respectivamente:

$M-d$ la siesta?

$M$ - aora t llamo.

F- a partir d ahora $t$ lo vy a dcir.

$M-m$ voy a dormir.

\subsection{Entonación}

Según Hidalgo y Quilis (2004), podemos definir la entonación como:

La curva melódica que describe la voz al pronunciar frases y oraciones: tal inflexión melódica guarda relación con las distintas representaciones mentales, con la expresión de los estados de ánimo y con la manifestación de hábitos y modos de decir y hablar locales (Hidalgo \& Quilis 2004: 235).

La entonación es "inherentemente significativa, esto es, expresa contenidos por sí misma: una determinada entonación confiere a una oración significados que no se desprenden de la pura secuencia de los elementos segmentales que componen ese enunciado" (Gil 2007: 329).

Siguiendo a Gil (2007: 364), podemos distinguir tres tipos de significados de la entonación: 
1. Significado Lingüîstico. Aquí se incluyen:

a) La función gramatical "que 'supuestamente' realiza la melodía con que se pronuncia una oración cuando nos indica la modalidad sintáctica a la que esta pertenece" (Gil 2007: 364).

b) La función discursiva en la que se distinguen: 1) la función demarcativa o delimitativa, esto es "la capacidad que la entonación posee para segmentar el discurso, dividiéndolo en fragmentos más pequeños, estableciendo los diversos tipos de límites que existen entre tales fragmentos y, consecuentemente sus interrelaciones y su organización interna; en una palabra, ayudando a los receptores a interpretar el mensaje" (Gil 2007: 366-367); 2) la función integradora, esto es "la capacidad de transformar las palabras en enunciados al dotarlas de significado comunicativo [...]. Es la estructuración entonativa la que dota de cohesión general al discurso" (Gil 2007: 369); 3) la función dialógica, esto es, la capacidad de la entonación "para segmentar y organizar la conversación mediante la regulación de los turnos de palabra" (Gil 2007: 369): 4) la función ilocutiva, esto es, la capacidad de la entonación para "variar o matizar la naturaleza ilocutiva de los enunciados o alterar sus efectos perlocutivos" (Gil 2007: 370); 5) la función informativa "se relaciona con lo que el hablante sabe o cree saber acerca de lo que el oyente conoce, y en función del cual manipula y estructura la información en su producción. Es decir que la entonación manifiesta la organización informativa del discurso [...]. Resalta el foco de la información y pone de relieve el contraste entre la información nueva y la información ya conocida por el oyente" (Gil 2007: 372).

c) La función sociolingüística. A través de la entonación "se marcan las características del grupo al que pertenece el hablante, su origen geográfico, su adscripción social y cultural, etc." (Gil 2007: 374).

2. Significado Paralingüístico. "De manera deseada conscientemente por el hablante o de modo inconsciente como un efecto 'pasivo' involuntario, la entonación proporciona indicios sobre el estado de ánimo permanente del emisor o sobre la emoción momentánea que lo embarga en el instante en que habla" (Gil 2007: 376). Según Gil (2007), los índices paralingüísticos modifican el modo en el que se realizan los rasgos tonales propiamente lingüísticos.

3. Significado Extralingüístico. "Cada hablante cuando emite sus enunciados tiende a moverse en una gama tonal determinada [...] la cual se 
corresponde con sus características personales, orgánicas, fisiológicas o temperamentales [...]. El campo de entonación que le es propio no coincide, pues, con el de los restantes locutores y eso permite que se lo pueda caracterizar o, incluso identificar por esas propiedades particulares de su forma de 'entonar' los mensajes." (Gil 2007: 378).

La importancia de la entonación para comunicar el verdadero contenido de nuestro mensaje hace que los usuarios de WhatsApp intenten encontrar convenciones gráficas que les ayuden de alguna manera a plasmar por escrito la entonación. Se intenta por todos los medios dar la sensación de que el texto escrito en WhatsApp debería ser, en realidad, habla.

\section{Significado lingüístico}

La función gramatical del significado lingüístico de la entonación se refleja sin demasiados problemas a través de los signos de puntuación que nos indican de manera clara las modalidades sintácticas de las oraciones que se utilizan.

Dentro de la función discursiva, presenta problemas la función demarcativa o delimitativa ya que en las interacciones en WhatsApp los signos de puntuación suelen estar ausentes y, por tanto, tenemos dificultades para segmentar el discurso. En lo referente a las funciones integradora y dialógica, el que el texto aparezca segmentado en fragmentos puede ayudar a dar cohesión general al discurso y a segmentar y organizar la conversación. Interesantes resultan los recursos relacionados con la función ilocutiva, ya que en este caso se suele recurrir a las composiciones icónicas -a los llamados emoticonos (analizados en el apartado dedicado a la comunicación no verbal) - que indican la naturaleza ilocutiva y perlocutiva de los enunciados. Respecto a la función informativa, se suele resaltar el foco de la información a través del uso estratégico de mayúsculas que ponen de relieve el contraste entre la información nueva y la información ya conocida por el oyente.

La función sociolingüística de la entonación resulta difícil de reflejar en el texto escrito. Lo más cercano sería la ortografía regional analizada anteriormente en la que se pueden observar algunos rasgos típicos del origen dialectal de los usuarios. 


\section{Significado paralingüístico}

En lo que se refiere al significado paralingüístico de la entonación, remitimos al lector al apartado dedicado a la comunicación no verbal en el que analizamos los recursos utilizados en WhatsApp para garantizar, de alguna manera, la presencia de paralenguaje en estas interacciones.

\section{Significado extralingüistico}

Por lo que respecta al significado extralingüístico, es difícil encontrar elementos gráficos capaces de reproducir por escrito la gama tonal propia de un hablante.

Como se ha puesto de manifiesto en este apartado, la escritura de las interacciones en WhatsApp se ve claramente influida por las reglas de pronunciación. Se producen una serie de cambios gráfico-fonológicos como consecuencia de la aplicación de rasgos de la lengua oral a la lengua escrita. Por otra parte, las limitaciones de espacio y la necesidad de fluidez y rapidez requerida por las conversaciones a través de esta aplicación conllevan la elisión de consonantes y vocales reduciendo al mínimo la palabra.

La necesidad de escribir y enviar rápidamente los mensajes provoca alteraciones ortográficas como la ausencia de acentos, el uso casi exclusivo de minúsculas, la no presencia de puntuación, la eliminación de letras que no se pronuncian, etc. Se trata de comunicar mucho en poco tiempo, y por tanto la escritura debe adaptarse a esas circunstancias. En definitiva, se da más importancia a la velocidad, precisión y concisión del enunciado que a la forma de este.

\section{Morfología}

Una de las características más llamativas del lenguaje utilizado en la comunicación mediatizada por ordenador, y por tanto, en las interacciones en WhatsApp, es el abundante uso de abreviaturas, acortamientos, siglas, acrónimos o truncamientos de palabras. Son muchos los investigadores que justifican esta tendencia a la abreviación haciendo referencia a las limitaciones impuestas por el medio utilizado. Así Sotomayor (2003) afirma que: 
Se han desarrollado estrategias lingüísticas muy innovadoras a fin de crear un registro lingüístico adecuado para la conversación y adaptado a las limitaciones del medio. Una de ellas es el reduccionismo taquigráfico o empleo económico del lenguaje mediante un registro cargado de abreviaturas que ayudan a reducir el desfase y así ahorrar esfuerzo y tiempo al teclear (Sotomayor 2003: 8).

La economía de esfuerzo y el ahorro en términos económicos son otras de las razones que se han aducido para justificar la abundancia de elementos abreviados:

Las abreviaturas contienen un valor ergonómico, puesto que al teclear menor cantidad de letras, se ahorra tiempo y energía; además dependiendo de la empresa proveedora del servicio, incluso la factura del teléfono se vería reducida. (Crystal 2002: 4).

Cuando el canal es lento, poco capaz o muy caro, las personas que intercambian información prescinden de los elementos más redundantes (Millán 2001: 182).

Aunque los motivos anteriores pueden, efectivamente, ser la causa inicial de la utilización de abreviaciones en la comunicación mediatizada por ordenador, los avances tecnológicos (mejora en la rapidez, no limitación de espacio, gratuidad del servicio) hacen que no se pueda seguir justificando el uso de abreviaciones por limitaciones del medio. Es por ello por lo que, probablemente, en la actualidad los motivos que llevan a utilizar este tipo de lenguaje abreviado en las interacciones en WhatsApp sean parecidos a los que justifican el auge de estos procesos morfológicos en la lengua en general. Según Almela Pérez (1999), el acortamiento es un mecanismo que está favorecido por la tendencia a la economía en el uso del lenguaje. Este autor señala como posibles causas de la aparición de los vocablos acortados la necesidad de manifestar valor apreciativo (juego, afectividad) o simplemente la comodidad de la brevedad. Para Varela (2005), en la creación de los acortamientos suele primar una intención afectiva, propia de la lengua familiar, aunque puede darse el caso de que el hablante reduzca las palabras simplemente por comodidad, para agilizar la expresión. Para Lang (1990: 262), "el avance del acortamiento [...] está en relación con la preferencia por un tipo de lenguaje sintético, acorde con los nuevos estilos de vida". 
El que este tipo de interacción sea principalmente utilizado por personas jóvenes ha hecho que se justifique el uso de las abreviaturas - a veces a modo de jeroglífico- como un medio a través del cual mostrar pertenencia al grupo. Así lo defienden autores como Escandell (2005) o Crystal (2002):

La limitación de espacio y las dificultades de escritura inherentes al uso del teclado telefónico para escribir texto propiciaron enseguida el desarrollo de un elevado número de abreviaturas. Muy pronto esta manera de escribir dejó de tener una finalidad exclusivamente práctica, para convertirse en el signo de identidad de los grupos juveniles, que representan el porcentaje mayor de usuarios de esta nueva forma de comunicación. Efectivamente, a pesar de que los avances tecnológicos han hecho más fácil la escritura [...], la mayoría de los jóvenes sigue prefiriendo utilizar las grafías abreviadas. [...] Esta práctica responde a un deseo de mostrar afiliación al grupo, y no simplemente una cuestión de economía del esfuerzo o del dinero. (Escandell 2005: 112).

El valor social de las abreviaturas, dado que estas formas fortalecen las relaciones de comunicación entre personas y grupos, crean formas muy creativas (Crystal 2002: 4).

En este apartado vamos a presentar de manera resumida algunos de los procesos de abreviación más frecuentes en las interacciones en WhatsApp. Para ello, distinguimos dos grandes tipos de abreviación: el acortamiento y la abreviatura.

El acortamiento, truncamiento o braquigrafía consiste en:

La reducción del significante de una palabra generalmente concretado en la pérdida de sílabas iniciales (aféresis) o finales (apócope), rara vez de sílabas intermedias (síncopa); el acortamiento consiste en la abreviación silábica (nunca de segmentos inferiores) del lexema base. El acortamiento es de índole fónica. Es la reducción fónica de una unidad léxica, sea palabra simple, sea palabra compuesta (Almela Pérez 1999: 202).

Según Varela (2005), los acortamientos pueden realizarse mediante:

1. Apócope: consisten en la elisión de la parte final de la palabra. 
2. Aféresis: consisten en la eliminación de la parte inicial de la palabra.

La abreviatura se define "como la reducción gráfica de una palabra o de un grupo de palabras; se pueden suprimir todas las letras menos la primera de las unidades afectadas" (Almela Pérez 1999: 203). Siguiendo la clasificación de Almela Pérez (1999), podemos distinguir varios tipos de abreviaturas en atención a dos criterios básicos:

1. Según el fragmento eliminado:

a) Regulares: lo que se elimina va correlativo en el lexema base. En este grupo puede actuar o solo el apócope, o solo la síncopa. Actúa la apócope si se elimina la parte última de la palabra. Actúa solo la síncopa si se elimina una parte intermedia de la palabra.

b) Convencionales: lo que se elimina no va correlativo en el lexema base. En este grupo actúan a la vez el apócope y la síncopa.

2. Según el resultado:

a) Simples: constan de un solo grupo. Pueden ser monogramas, digramas, trigramas, tetragramas, etc.

b) Dobles: forman su plural repitiendo la letra que constituye la abreviatura simple.

c) Compuestas: son el resultado de la reducción de fórmulas.

Teniendo en cuenta esta clasificación, a continuación, analizamos los acortamientos y abreviaturas en las interacciones en WhatsApp.

Los acortamientos por pérdida de sílabas finales son muy frecuentes en las interacciones en WhatsApp. Los casos más frecuentes son los de nada y para acortados como na y pa:

F- pos na vy a ir a jugar el partido.

A- onde tas? Pa darte el dinero.

Es muy frecuente también el acortamiento por apócope de la palabra pelicula que suele aparecer como peli:

M- vy a csa q ems pillao pa ver una peli jiji. 
Otro fenómeno frecuente en las interacciones en WhatsApp son los acortamientos por aféresis. Es el caso de los verbos estar y esperar que suelen ser acortados y aparecen con formas como: sta, tas, pera y/o spera:

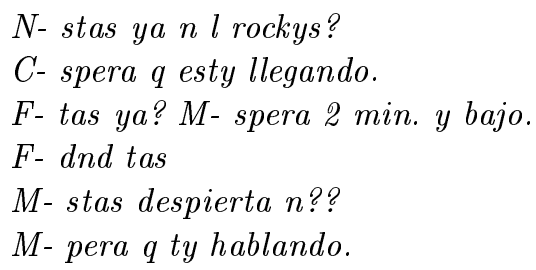

En este tipo de interacciones, se cumple la tendencia general en los procesos de acortamiento en español, y son prácticamente inexistentes los fenómenos de acortamiento por síncopa.

Son frecuentes en este tipo de conversaciones los acortamientos de sintagmas. El caso de por favor es el más característico. Los participantes tienden a acortar el sintagma utilizando la forma porfa:

M- puedes traer hoy l camara porfa.

Entre las abreviaturas regulares más habituales en este tipo de lenguaje destacamos las siguientes:

1. Las palabras minuto y número se abrevian como min y num, respectivamente. Como puede observarse, se produce en ambas una abreviación por apócope: $M$-dos min y bajo. P-dame tu num q $t$ yamo.

2. La palabra bien se abrevia mediante síncopa eliminando exclusivamente las vocales: bn: $A$ - a mi me parece todo bn jiji.

3. La abreviatura de que a través de apócope con la forma $q$ empieza a ser frecuente, aunque sigue compitiendo con la grafía $k$ : $C$ - mañana $k$ aces? $M-q$ dices??

4. Una de las abreviaturas más conocidas es la forma reducida de la palabra inglesa okey; ok.

5. Se producen asimismo abreviaturas regulares de las palabras me, te, se, $l a, d e$, en que aparecen como $m, t, s, l, d, n$, respectivamente: $A$ - sta tarde puedes dar l clase d irene. 
6. Se produce apócope o síncopa en la palabra aunque que puede aparecer abreviada como aunq o aunqe: $M$ - disfruta muxo de tu dia aunq se $q$ tb estas liada. C-yo quiero ir aunque él no creo q qiera.

7. La forma estoy suele abreviarse como esty: A- esty en la calle alguien bja.

8. Es frecuente la abreviatura de voy como vy: $S$ - aora $v y$.

9. Luego y poco se abrevian como lgo y pco, respectivamente: $M$ - lgo cnd acabe $t$ aviso. $C$ - m keda pco para acabar ya.

Entre las abreviaturas convencionales en las que se produce simultáneamente apócope y síncopa destacan las siguientes:

1. Es frecuente la abreviatura de también como $t b$ y/o tmb: A- ya yo tb llevo tdo l dia cn trbjos.

2. Una forma rápida y eficaz de pedir una respuesta al receptor es la abreviatura de la palabra contestar en cnt. Esta misma abreviatura se utiliza para cualquiera de las formas no personales del verbo (contestar, contestado, contestando): $N$ - podeis cnt os dejo jaja. M- t estaba cnt...

3. La preposición por suele sustituirse por $x$, probablemente por la influencia del área de las matemáticas del signo de multiplicar y por la transcripción fonética del sonido del signo. A partir de ella se derivan las formas abreviadas de la palabra porque en: $x k, x q$, entre otras, aunque estas son las más frecuentes: $C$ - xk kieres ir a tomar algo?

4. Una de las abreviaturas más utilizadas como fórmula de despedida es la abreviatura de las palabras beso o besos, bs y bss, respectivamente. En ambas se producen simultáneamente los fenómenos de síncope y apócope: F- nos vemos mañana un bs. D- ok bss! También encontramos la abreviatura para el sustantivo diminutivo besito o besitos que suele aparecer como bsito y bsits, respectivamente: $M$ - aioo muaa bsts!

5. La palabra mañana se abrevia como mña o como mñna: $M-m \tilde{n} n$ ya ns verems. C- ta mñna.

6. La palabra tampoco se abrevia mediante la aplicación simultánea de síncope y apócope y aparece con las formas tmpc o tmp: $M$ - ni idea tmpoc han dixo nada n? D- yo tmp lluna.

7. Los mismos recursos se utilizan para abreviar la palabra donde como $d n d$ o dnde: $C$ - $m m m$ dnd estas $x D$. A-ondee staaas?? Esta palabra se abrevia también mediante la aplicación de aféresis obteniendo la forma onde: $A$ onde tas?

8. En el caso de la palabra todo se eliminan una o las dos vocales y se utiliza la abreviatura $t d$ o tdo: J- tngo td listo ya. J-entra tdo lo q ems dao. 
9. Las palabras como y con se abrevian dando lugar a las formas $\mathrm{cm}$ o $\mathrm{cmo}$ y cn: A-jaja cm t gusta $x D$. A-bn cmparad cn el opel. D-cmo lo hago?! $C$ - he quedao aoa con ella vente.

10. Los mismos fenómenos se producen en el caso de cuando y tengo abreviados como, cnd y tng, y aunque en menor medida, cndo y tngo. $C$-pero yo lo tng $k$ entregar ya. $C$ - cndo lo acabe $t$ aviso.

11. Un caso particular es la forma abreviada de la palabra entonces. Esta palabra puede abreviarse mediante abreviatura regular tonces o utilizando una abreviatura convencional del tipo ntces: $M$ - ntces q acemos?

La mayor parte de las abreviaturas utilizadas en WhatsApp son simples. Entre las abreviaturas simples monogramas, las más características son las que abrevian que con $k$ o $q$, y la abreviatura de no y en con la letra $n$. Aunque se tiende siempre a reducir las palabras, las abreviaturas monogramas son las que se encuentran en menor medida puesto que pueden provocar ambigüedades en el mensaje. Los digramas suelen ser los más comunes ( $b n, o k)$, aunque los trigramas son también frecuentes (min, num, tmb).

Aunque las abreviaturas más frecuentes son las simples, también es posible encontrar abreviaturas dobles, como por ejemplo la palabra beso que encontramos abreviada como bs y cuyo plural se abrevia bss, con reduplicación de la sibilante únicamente.

En lo que se refiere a las abreviaturas compuestas -esto es la reducción de fórmulas-, una de las primeras que apareció en este tipo de lenguaje por influencia del inglés es la forma $L O L$ que abrevia la fórmula Laughing out loud, expresión que indicia que el participante se está riendo: $V$ - me parto jaja. G- jajajaja lol xd.

Relacionada con la anterior, encontramos abreviada la expresión francesa Mort de rie que aparece como $m d r$.

Entre los casos más característicos de abreviaturas compuestas se encuentran: es que abreviado como esq; no sé abreviado como ns; para allí abreviado como palli; para el abreviado como pal; para que abreviado como pake; para arriba abreviado como parriba; para abajo abreviado como pabajo.

También se producen abreviaturas del tipo tol por todo el y taluego por hasta luego: P-taluego. M-llevas tol dia enfdao cnmgo.

Las abreviaciones también se mezclan con ingeniosos juegos de palabras que hacen aún más corta la extensión de la palabra pero que mantienen intacta 
la información que quieren transmitir. Ejemplos como los que señala Yus (2001) para el chat son muy frecuentes en WhatsApp:

Finalmente, la creatividad en los chats se manifiesta con juegos de palabras, paranomasias o coincidencias sonoras: "d2" ("dedos", en castellano); "a10" ("adéu" -"adiós"- en catalán); "u r", "uno" ("you are" y "don't know", en inglés). Truncamientos, juegos de palabras: "cu 18er"- see you later. (Yus 2001: 145).

Asimismo, es común utilizar siglas y acrónimos para conseguir mayor rapidez en la comunicación: D- Bueno yo no hago TFG pero tng una presentación el jueves de una hora.

\section{Sintaxis}

En el aspecto sintáctico, una de las características más relevantes del llamado ciberlenguaje es el descuido y el alejamiento respecto a las normas gramaticales establecidas. Por otro lado, el estilo coloquial de las interacciones comunicativas a través de WhatsApp favorece el uso de un determinado tipo de estructura sintáctica muy cercana a la habitual en las conversaciones informales cara a cara. Como afirma Pano:

La sintaxis refleja la informalidad típica de la conversación combinada con la necesidad de ocupar el menor espacio posible en una línea dando el mayor número de informaciones (Pano 2009: 12).

En este apartado presentamos algunas de las características sintácticas más relevantes de las interacciones en WhatsApp. Hablamos en primer lugar de tipología oracional. A continuación, nos centramos en la estructura de las oraciones haciendo especial hincapié en los usos incorrectos, en las elipsis y en el orden de palabras. En tercer lugar, nos ocupamos de las categorías gramaticales predominantes en los mensajes en WhatsApp. Finalmente hacemos una breve referencia a las funciones comunicativas predominantes en WhatsApp y a las estructuras sintácticas relacionadas con ellas. 


\subsection{Tipología Oracional en WhatsApp}

Podemos decir que respecto a su estructura interna, las oraciones en WhatsApp suelen ser simples. Este tipo de estructura favorece la rapidez y la agilidad que requieren estas interacciones que intentan reproducir el dinamismo de la conversación cara a cara.

Son frecuentes también, las oraciones coordinadas y yuxtapuestas. Entre las oraciones coordinadas, el tipo más habitual es el de las copulativas seguidas de las disyuntivas y las adversativas. Menos habituales son las oraciones coordinadas distributivas y explicativas.

Por el contrario, el uso de oraciones subordinadas es muy escaso. No obstante ciertas estructuras adverbiales como las siguientes pueden encontrarse: subordinadas adverbiales locativas: I- ns llevams el coche y aparacms dnde podamos (en lugar de "allî"); subordinadas adverbiales temporales: $M$ - ire cndo termine esto sin es imposible (en lugar de "iré luego"); subordinadas adverbiales modales: A- hazlo cm puedas pero intentalo (en lugar de "hazlo asî").

Según la naturaleza del verbo predominan las oraciones predicativas. Las más frecuentes son las transitivas.

Según la modalidad oracional, en las interacciones en WhatsApp predominan las oraciones asertivas, declarativas o enunciativas, en las que se exponen los hechos llevados a cabo por los participantes. Son también muy frecuentes las oraciones interrogativas y las exclamativas, ya que en muchas de estas interacciones se pretende obtener información, dar consejos o expresar las emociones del emisor.

\subsection{Estructura de la Oración}

Una de las características sintácticas más llamativas de este tipo de interacciones es el elevado número de elipsis y omisiones de elementos fundamentales de la estructura oracional. En muchas ocasiones se elimina el verbo. El emisor entiende que solo con el sustantivo o el adjetivo el receptor podrá descodificar el mensaje y por tanto, evita perder tiempo en teclear el verbo. Los verbos que con mayor frecuencia se eliden son los verbos copulativos ser y estar y el auxiliar haber, y verbos con carácter temporal, es decir, verbos que suelen ir acompañados de estructuras sintácticas temporales o espaciales, como quedar a una hora, quedar en algún lugar, etc. En algunas ocasiones, estas elipsis verbales pueden dar lugar a ambigüedad en el mensaje. 
Algunos ejemplos de elipsis verbales son los siguientes:

D- Atasco por "Estoy en un atasco."

$J$ - Alguien en el bar? por "¿Hay alguien en el bar?"

$C$ - hora? por "¿A qué hora quedamos?"

$P-t$ paso? por "¿Te paso a buscar o te paso a recoger?"

$M$ - donde? por "¿Dónde quedamos?"

A- 10 min vermú por "En diez minutos vamos a tomar un vermut."

$A$ - rockys? por "¿Quedamos en el rockys?"

$M$ - voy hacia alli $L L-$ ya? por "¿Ya estás aquí?" o "¿Ya vienes?"

$M-q$ tal? por "¿Qué tal estás?"

$C$ - agobiada por "Estoy agobiada".

Es frecuente también la elisión de preposiciones y artículos, como muestran los siguientes ejemplos:

F- voy dbjo tu csa (debajo de).

I- si alguien $n$ lo parece bn q lo diga (a alguien)

F- dnd stas?

$D$ - portal (en el portal)

$N$ - sta noxe dnd vams?

$V$ - sol de nit? $x D$ (al sol de nit)

$L$ - alguien viene $x$ mi plis no tng coxe (a por mí)

$M$ - qdmos?

$C$-hora? (¿A qué hora?)

$P$ - dnd estais?

$N$-Bar (en el bar)

$M$ - $q$ vas hacer? (a hacer)

Entre los errores sintácticos más frecuentes destacan los siguientes:

1. El uso incorrecto de preposiciones y pronombres: $P$ - poneros el juego al movil $q$ mola.

2. Errores de concordancia sintáctica entre sujeto-verbo y determinantesustantivo: A- quien bajais?

3. Elecciones erróneas del modo verbal.

4. Uso de frases inacabadas: $C$ - vienes o q? P-esq si vy... 
En las interacciones en WhatsApp son muy frecuentes los procesos de tematización y rematización en los que el emisor altera el orden de palabras para destacar determinados elementos dentro de la oración. El siguiente intercambio es un ejemplo de este tipo de fenómenos:

\section{C- enseriooo?? Fatal me aparece!}

\subsection{Categorías Gramaticales}

Respecto a las categorías gramaticales, podemos decir que en las interacciones en WhatsApp abundan los demostrativos y pronombres que ayudan a esclarecer la persona u objeto del que se está hablando y a evitar ambigüedades: $C$ $q$ haces este sabado? $M$ - tú tienes apuntes de siglos?

Son también muy abundantes los adverbios y construcciones adverbiales de lugar y tiempo como ahora, ya, aquí, alli, arriba.

$$
\begin{aligned}
& C \text { - vienes ya } \\
& M \text { - si ya vy } \\
& \text { C- vente par aqi } \\
& P \text { - esprarme q ya vy palli }
\end{aligned}
$$

Observamos, asimismo, un uso frecuente de adverbios de modo como bien, mal, asi y de adverbios de cantidad como mucho, poco, bastante.

$$
\begin{aligned}
& C-c m \text { va? } \\
& M-\text { mal n e acabdo }
\end{aligned}
$$

M- creo q ya tng bstnate cn lo q $m$ has enviado D- nse si iré tngo mu poco dinero

Respecto a los verbos, debemos destacar que el tiempo verbal más frecuente es el presente de indicativo. En general predominan los tiempos verbales simples frente a los compuestos.

Respecto a los sustantivos hay que destacar el uso frecuente de sustantivos derivados mediante sufijación apreciativa, ya sean diminutivos, aumentativos o peyorativos. 
A- mi coche nuevitoo!

C- es pqueñito pro esta bn jeje.

F- q morrazo q tienes!

$C$ - me parece de niñato.

Por último, en lo referente a las conjunciones, predominan las conjunciones copulativas seguidas de las disyuntivas, adversativas y, en menor medida, las distributivas.

\subsection{Funciones Comunicativas Predominantes en WhatsApp y Estructuras Sintácticas Relacionadas}

En este último apartado, nos ocupamos de las funciones comunicativas predominantes en el WhatsApp con el objetivo de poner en relieve la presencia de las estructuras sintácticas relacionadas con ellas.

En las interacciones en WhatsApp predominan las funciones expresiva, conativa y fática. Teniendo en cuenta esto, abundan los recursos propios de estas funciones como son los vocativos, imperativos o fórmulas de mandato, las interrogaciones normales y retóricas y las interjecciones.

La función expresiva es fundamental en este tipo de conversaciones, ya que una de los objetivos principales de estas interacciones es expresar las opiniones, sentimientos o deseos de los participantes.

La función conativa es también muy relevante en este tipo de conversaciones, ya que en muchas ocasiones los participantes utilizan estas interacciones para aconsejar, dar órdenes, expresar deseos, etc.

Por otro lado, para mantener la conversación y que ésta sea factible, es necesario que se utilicen recursos que garanticen el contacto y que verifiquen el funcionamiento del canal. Por tanto, la función fática tiene un papel fundamental en este tipo de interacciones en las que se carece de control visual del interlocutor.

\section{Léxico}

Los aspectos relevantes, en el ámbito del léxico, en las interacciones en WhatsApp son básicamente tres: 1) importancia de la iconicidad; 2) abundante uso 
de onomatopeyas e interjecciones; y 3) uso de un tipo de léxico particular en el que abundan los anglicismos y los coloquialismos. A continuación abordamos brevemente estas tres cuestiones.

\subsection{Iconicidad}

Los fenómenos sígnicos son característicos de los seres humanos porque viven en sociedad y forman parte de los códigos que rigen las relaciones sociales entre ellos. La definición clásica de signo es la proporcionada por Peirce según la cual el signo es "algo que está para alguien en lugar de algo en algún respecto o capacidad" (citado por Hierro 1989: 24). Peirce distingue tres clases de signos:

1. Índices o signos indéxicos: En ellos "hay una relación de efecto a causa, en el sentido de que tomamos algo como signo de otra cosa en la medida en que ha sido causalmente afectado por ella" (Hierro 1989: 24).

2. Iconos o signos icónicos: "Son aquellos que se refieren a un objeto en razón de sus caracteres propios, lo que quiere decir que algunos de tales caracteres corresponden a los del objeto, y por tanto que entre el signo y el objeto existe una relación de semejanza" (Hierro 1989: 24).

3. Símbolos o signos simbólicos: "Son aquellos cuyo carácter de signo obedece solo o principalmente al hecho de ser así utilizados, y los cuales carecen, por tanto, de relación propia con el objeto significado" (Hierro 1989: 25).

Los iconos o signos icónicos son divididos por Peirce en tres subclases (Sebeok 2001: 92; Alonso-Cortés 2002: 52):

1. Imágenes en las que la relación icónica entre interpretado e interpretante es de semejanza directa. Se trata de un signo que participa de las cualidades del objeto. Por ejemplo: una foto.

2. Diagramas en las que la relación icónica concierne la relación entre las partes representadas por medio de relaciones análogas. Se trata de un signo que representa relaciones entre las partes de un objeto. Por ejemplo: un diagrama.

3. Metáforas que representan un paralelismo. Se trata de un signo que representa al objeto mediante un paralelismo con otra cosa.

Nos interesa destacar el frecuente uso en WhatsApp de elementos icónicos (imágenes, diagramas y metáforas) en términos de Peirce. Se trata de un 
lenguaje específico de la comunicación electrónica, un lenguaje que está constituido por multitud de iconos aplicables a diferentes situaciones. El objetivo de estos elementos es expresar el significado de manera fácil e ingeniosa. El uso de estos signos icónicos permite ahorrar tiempo -ya que debemos pulsar una única tecla- garantizando la inteligibilidad del mensaje. Por tanto, la economía del texto y la propensión al ahorro de palabras justifican el uso de estos elementos icónicos que permiten sustituir palabras o frases enteras por un solo elemento.

Las imágenes son muy habituales en las interacciones en WhatsApp. La Figura 1 ofrece solo algunos ejemplos de las múltiples posibilidades que ofrece esta tecnología.

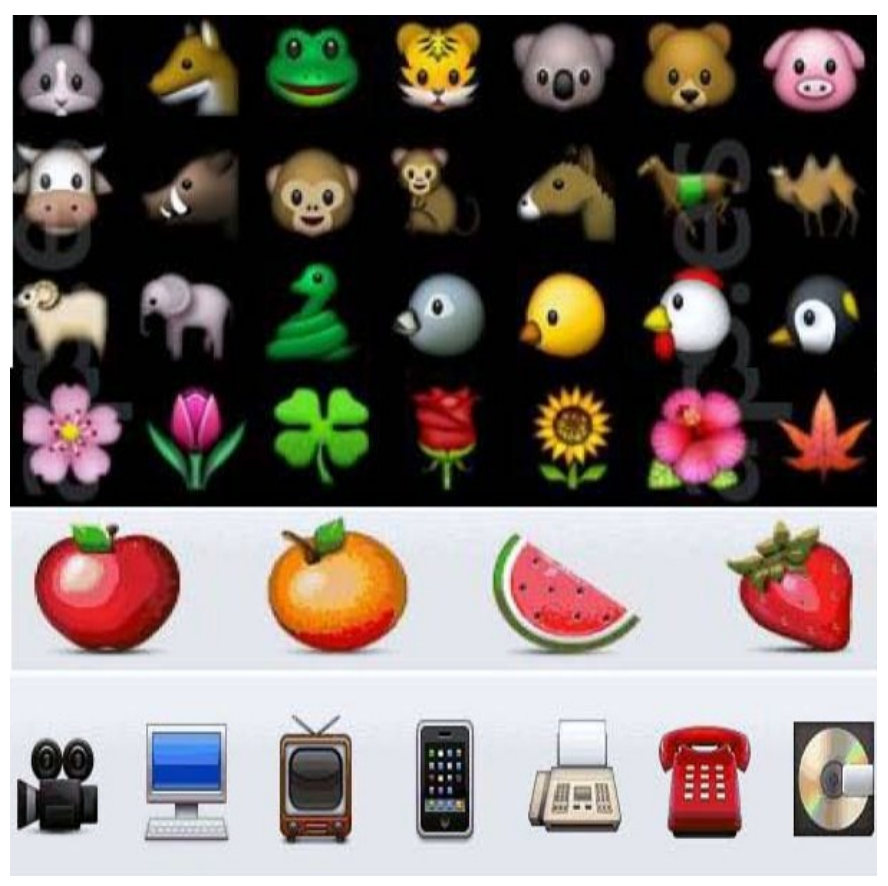

Fig. 1. Imágenes en WhatsApp.

No son habituales en las interacciones en WhatsApp los diagramas-signos que representan las relaciones entre las partes de un objeto. El carácter in- 
formal y la naturaleza discursiva y no transaccional de las conversaciones en WhatsApp justifican la ausencia de diagramas.

Son, en cambio, muy frecuentes las metáforas -signos que representan al objeto mediante un paralelismo con otra cosa. La Tabla 1 siguiente recoge algunos ejemplos de este tipo de signos.

\begin{tabular}{|c|c|}
\hline ICONO: Metáfora & Significado \\
\hline & dormir \\
\hline & enamoramiento \\
\hline e. & desamor \\
\hline & matrimonio \\
\hline & Iluvia \\
\hline & muerte \\
\hline نे & fiesta \\
\hline & beso \\
\hline & \\
\hline
\end{tabular}

Table 1. Metáforas en WhatsApp. 


\subsection{Uso de Onomatopeyas e Interjecciones en WhatsApp}

Relacionado directamente con el uso de un lenguaje icónico, se encuentra la frecuente utilización de onomatopeyas e interjecciones. La clasificación de onomatopeyas e interjecciones ha estado sujeta a discusión. Según Hierro Pescador (1989: 35) las onomatopeyas "serían, al menos en parte, imágenes, puesto que se refieren a un objeto en la medida en que se asemejan al ruido que produce ese objeto". De la misma opinión es Sebeok (2001: 57) quien afirma que "anche le parole onomatopieche sono segni iconici perché simulano i loro referenti in modo acustico". Para Saussure, en cambio, las onomatopeyas y las interjecciones son signos simbólicos y, por tanto, arbitrarios:

Se podría uno apoyar en las onomatopeyas para decir que la elección del significante no siempre es arbitraria. Pero las onomatopeyas nunca son elementos orgánicos de un sistema lingüístico. [...] En cuanto a las onomatopeyas auténticas (las del tipo glu-glu, tic-tac, etc.), no solamente son escasas, sino que su elección ya es arbitraria en cierta medida, porque no son más que la imitación aproximada y ya medio convencional de ciertos ruidos (Saussure 1916: 91-92).

Las exclamaciones, muy vecinas de las onomatopeyas, dan lugar a observaciones análogas y no son más peligrosas para nuestra tesis. Se tiene la tentación de ver en ellas expresiones espontáneas de la realidad, dictadas como por la naturaleza. Pero para la mayor parte de ellas se puede negar que haya un vínculo necesario entre el significado y el significante. Basta con comparar dos lenguas en este terreno para ver cuánto varían estas expresiones de idioma a idioma (Saussure 1916: $92)$.

Crystal (2002: 191) señala la transcripción de onomatopeyas emocionales y las interjecciones como uno de los rasgos fundamentales del ciberhabla. El frecuente uso de interjecciones y onomatopeyas en las interacciones en WhatsApp puede justificarse por el tipo de conversaciones (informales y no transaccionales) que suelen mantenerse a través de esta aplicación en las que, como afirma Moral y García (2003), se produce un mayor grado de comunicación socio-emocional. Para Sotomayor y Eliana (2003), el uso de interjecciones y onomatopeyas "tienen como objetivo tornar el diálogo más informal y divertido entre los participantes". 
Entre las onomatopeyas e interjecciones más frecuentes se encuentran: jeje, jaja, jiji, jojo, uff, ehh, mmm, buuff, pff, ahhgggrrr. Los ejemplos siguientes recogen algunos de estos usos:

A- a mi me parece todo bn jiji.

A- jajaj y eres tu qien lo ha recordao.

$M$ - Almir $t$ deja hacrlo otro dia $x D$.

M-ya jeje.

A- [...] llevo toda la nche liada buuuuufffff.

$F$ - vas a venir??

$M-m m m$. . nse.

$C$ - pfff no puedo mas no creo $q m d$ tiempo...

A- Yujuu se acabo el bus! Almns alngs dias! Yupiiii!

P-Ahhggggrrr $Q$ assssscooooo!!

$P$ - ehh q no hablais.

En el apartado dedicado a la comunicación no verbal retomaros el análisis de este tipo de elementos que pueden englobarse en el paralenguaje.

\subsection{Tipo de Léxico}

Un rasgo característico del lenguaje utilizado en las interacciones en WhatsApp es el uso frecuente de préstamos, sobre todo de anglicismos. Son muchos los autores que destacan la presencia de este tipo de elementos:

También es fácil encontrar en la Red el Espanglish, un fenómeno utilizado tanto en la Red como en otros ámbitos. Esa mezcla de inglés y de español, de anglicismos adaptados al español sin ningún criterio lingüístico, y de la traducción literal de muchos de ellos (Devís 2004: $73)$.

Además de anglicismos, es frecuente encontrar casos de galicismos e italianismos, sobre todo en los saludos y fórmulas de agradecimiento: merci, thanks, cao, ciao, bye, $d w$ (en catalán), OK. Ejemplos de estos préstamos se recogen en los siguientes fragmentos de conversaciones en WhatsApp: 
D- Ho sentooo acabo de leer el grupo. Yo voy a la biblio right now. $f$ - vale Money Money ee.

$M-Q$ psa yet set!

$M$ - Podrias hacrme un favor plis?

$J$ - mercii nenitaa nos vemos luego un bs.

I- ok ns vemos ciaooo!

$d$ - vale amores dww.

$N$ - tngo q irme hblams ok? Byeee muaa.

La informalidad que caracteriza a las interacciones en WhatsApp justifica un elevado número de coloquialismos y elementos léxicos jergales. Como afirma Álvarez (2011: 2), "la presencia de coloquialismos y expresiones propias del lenguaje oral es una de las características más destacadas" de este tipo de lenguaje. También Cervera (2013: 15) destaca "el tono distendido, jovial y coloquializador con que hablan los participantes" en estas interacciones. Los siguientes ejemplos ponen de manifiesto este tipo de lenguaje:

M- hems qdao pa ver una peli $n$ mi csa.

$V$ - salimos?

$S$ - nse tio no tng pasta.

L- a ls $10 t$ pillao $h$ en l pelu jiji.

F- tio t lo dije ayer joder. . aora q?!

A- mi camara.

$M$ - ostiaa ya se $m$ olvidaba jaja $x D$.

C- ostia cmo rayas tio callate ya.

F- eso q taladras pirate a dormir.

Siendo los jóvenes los que hacen un mayor uso de la aplicación WhatsApp, es fácil entender que la jerga más habitual en estas interacciones sea la juvenil. Como afirma Pano (2008: 6), "el léxico refleja el uso del lenguaje común [...] y sobre todo jerga juvenil".

El carácter informal de estas interacciones hace que sea difícil encontrar cultismos y tecnicismos. Salvo en conversaciones en las que se habla de un tema concreto -que puede ser técnico-, lo normal es que predomine el lenguaje coloquial. 


\section{Pragmática: Estructura de la Conversación}

En este apartado, nos vamos a centrar en la estructura de las interacciones en WhatsApp. Teniendo en cuenta que uno de nuestros objetivos es determinar si estas interacciones pueden calificarse de conversacionales, la primera sección de este apartado se dedica a analizar si las características propias de las conversaciones cara a cara se cumplen en los intercambios comunicativos en WhatsApp. Respondida la pregunta fundamental, analizaremos la estructura de la conversación fijándonos especialmente en el contexto y los participantes, las técnicas de coordinación utilizadas, el mantenimiento de la coherencia y la fase de cierre.

Limitaciones de espacio impiden que analicemos en este apartado otras cuestiones pragmáticas relevantes. Interesante sería observar cómo se maneja el cálculo del significado implícito en estas interacciones. En general, un análisis poco profundo indica que el cálculo de las implicaturas no difiere del realizado en las conversaciones cara a cara. Para un estudio profundo sobre ciberpragmática, sobre todo en lo referente a la aplicación de la teoría de la relevancia en estas interacciones, el lector puede consultar Yus (2001, 2010). El estudio de la argumentación discursiva y el uso de actos de habla indirectos en estas interacciones es otra de las posibles vías de investigación que podría arrojar resultados interesantes. Especial interés tendría el estudio de la cortesía como estrategia conversacional en este tipo de interacciones, sobre todo teniendo en cuenta que las conversaciones en WhatsApp pueden calificarse como discursos interactivos (no transaccionales) en los que, por definición se da prioridad a las reglas impuestas por el principio de cortesía.

Two global distinctions between discourse types have been proposed that bear on the quality and quantity of politeness. Transactional discourse types focus on the optimally efficient transmission of information [...]: Conversational behavior that is consistent with the requirements of transactional discourse will thus be characterized by close observance of the Cooperative Principle. Interactional discourse, by contrast, has as its primary goal the establishment and maintenance of social relationships. In interactional discourse, therefore, the Cooperative Principle is regularly overridden by the Politeness Principle in order to ensure that participants' face-wants are taken care of (Kasper 1990: 205). 


\section{1 ¿Son las Interacciones en WhatsApp Conversaciones?}

Para determinar si las interacciones en WhatsApp son o no conversaciones, presentamos a continuación algunas de las definiciones y características que se atribuyen a los intercambios conversacionales.

Una interacción es "cualquier acción conjunta, ya sea conflictiva, cooperativa, en la que se ponen en relación dos o más actores" (Portolés 2004: 67). La conversación es el tipo de interacción verbal más habitual y se caracteriza por ser (Portolés 2004: 68):

1. Oral: se articula por medio del canal fónico.

2. Dialogal: tiene una sucesión de intervenciones.

3. Inmediato: se desarrolla en la coordenada espacio-temporal aquí-ahoraante ti.

4. Dinámico: por la continua permuta y cambio de papeles entre los interlocutores (de hablante a oyente, de oyente a hablante).

5. Cooperativo: se obra juntamente con otro.

Para Clark (1996), las características de la conversación son las siguientes:

1. Copresence. The participants share the same physical environment.

2. Visibility. The participants can see each other.

3. Audibility. The participants can hear each other.

4. Instanteneity. The participants perceive each other's actions at no perceptible delay.

5. Evanescence. The medium is evanescent -it fades quickly.

6. Recordlessness. The participants' actions leave no record or artifact.

7. Simultaneity. The participants can produce and receive at once and simultaneously.

8. Extemporaneity. The participants formulate and execute their actions extemporaneously, in real time.

9. Self-determination. The participants determine for themselves what actions to take when.

10. Self-expression. The participants take actions as themselves.

Si tenemos en cuenta la clasificación de Portolés (2004), las interacciones en WhatsApp pueden calificarse de conversacionales, ya que estas cumplen todas las características establecidas excepto la primera; el canal no es oral, sino escrito. La interacción en WhatsApp es dialogal, ya que se compone de una 
sucesión de intervenciones. Es inmediata: se produce en un espacio-temporal real, aunque no físico sino virtual, y del que se espera lo antes posible la respuesta. Es dinámica, ya que se van intercambiando los papeles de los interlocutores. Y, por último, es cooperativa, ya que se necesita la colaboración de los interlocutores.

Si seguimos la clasificación de Clark (1996), las interacciones en WhatsApp se revelan también como conversacionales. En ellas es necesaria la co-presencia de los participantes, aunque está no sea física sino virtual. Los participantes están visibles los unos para los otros, saben con quién pueden conversar porque la conexión de los usuarios es visible para los miembros de la aplicación. La audibility -que los interlocutores puedan escucharse- no es una condición básica, puesto que el canal es escrito y no oral por lo que realmente se basa en la visibilidad de la escritura. No obstante, se pueden grabar mensajes de audio y enviarlos para que sean escuchados. Es instantánea, ya que se produce en un tiempo real y no hay largas demoras. Es evanescente, pues el medio puede desvanecerse en cualquier momento y además los participantes pueden eliminar los mensajes que envían; es simultánea ya que, se puede enviar y recibir información al momento. Es extemporánea porque los participantes formulan y ejecutan sus acciones en tiempo real. Tiene un carácter autodeterminativo, ya que los participantes son los que deciden y determinan por sí solos qué acciones tomar o cuándo. Y, por último, tiene carácter autoexpresivo es decir, los participantes se expresan como quieren, no se pacta cómo se ha de expresar.

Además de adecuarse a las características señaladas por Portolés (2004) y Clark (1996), las interacciones en WhatsApp satisfacen los requisitos impuestos para que una interacción pueda calificarse como conversacional, a saber:

1. Se produce el cambio de hablante.

2. Una parte habla en cada momento.

3. Ocurrencias de más de un hablante son comunes, pero breves.

4. Transiciones sin lapsos y sin solapamientos son comunes.

5. Orden de los turnos no fijo, sino que varía.

6. Tamaño de los turnos no fijo.

7. Duración de la conversación no fijada de antemano.

8. Lo que las partes dicen no está especificado.

9. Distribución de los turnos no especificada.

10. Número de partes puede variar. 
11. Se observan técnicas de asignación de turno.

12. Existen varias unidades estructuradoras de turno (palabra, cláusula, ... ).

13. Hay mecanismos de corrección.

Teniendo en cuenta que, como hemos visto, las interacciones en WhatsApp pueden calificarse como conversaciones, a continuación analizamos los elementos y técnicas básicas en estos intercambios conversacionales.

\subsection{Contexto y Participantes en las Interacciones en WhatsApp}

En cualquier conversación encontramos dos elementos esenciales: contexto y participantes. No hay conversación si no tenemos al menos dos participantes y, por supuesto, cualquier conversación tiene lugar en unas coordenadas espaciotemporales y bajo la asunción de un conocimiento compartido por los participantes.

El contexto es fundamental para entender toda conversación. El contexto incluye una gran cantidad de conocimiento compartido por los hablantes. Muchas son las definiciones de contexto que se han propuesto, cada una de ellas considerando elementos diferentes. Lo que parece común a los varios tipos de definiciones es que el contexto tiene que hacer referencia a factores relevantes para entender el intercambio comunicativo y que tiene que ser compartido por todos los participantes. El contexto determina las acciones que los hablantes realizan. Frente a los grupos asincrónicos -aquellos en los que la conversación no se establece en un tiempo real, es decir, cuando los mensajes quedan grabados pero las contestaciones se van produciendo a lo largo del tiempo-, el WhatsApp se caracteriza por ser una aplicación sincrónica. En WhatsApp se puede saber si un participante está conectado o no, o cuál ha sido su última conexión. Esto permite que los participantes escriban sus mensajes en tiempo real y que las conversaciones se mantengan en tiempo real, es decir con los participantes compartiendo la coordenada temporal. Ésta es una de las características que de manera más clara distingue las interacciones en WhatsApp de los mensajes SMS o de las sesiones de chat.

Evidentemente, las características de estas interacciones hacen que, por definición, no se produzcan en un espacio real físico compartido. El espacio es claramente virtual, pero compartido, ya que no se pueden mantener conversaciones con miembros que no estén dentro del espacio virtual (red) de la aplicación. Así un participante A no podrá mantener una conversación con 
un participante B si éste no utiliza la aplicación de WhatsApp. El espacio virtual puede ser compartido directamente en el mismo momento en el que los participantes disponen de la aplicación.

En la mayor parte de las conversaciones en WhatsApp, los participantes se conocen, ya que normalmente son las personas que componen la agenda de contactos de cada usuario. Este hecho garantiza el conocimiento compartido (lingüístico y extralingüístico) necesario para mantener la conversación. No obstante, es posible, a través de una conversación múltiple (grupo), conversar con personas a las que no se conoce. Esto produce, en ocasiones, ambigüedades o falta de entendimiento entre los participantes que no comparten el conocimiento necesario.

Respecto al número de participantes, en las interacciones en WhatsApp, este puede variar dependiendo del tipo de conversación. En general, en las conversaciones privadas/personales suelen intervenir únicamente dos participantes. Por el contrario, las conversaciones múltiples permiten un número muy elevado de participantes. Durante la conversación, pueden entrar y salir participantes. Los usuarios pueden crear grupos incluyendo en ellos los participantes que deseen y estableciendo el nombre del grupo.

\subsection{Coherencia en las Interacciones en WhatsApp}

En general, los diversos autores están de acuerdo en que para obtener una conversación coherente no es necesario tener un conjunto de participantes hablando sobre el mismo tema. Los hablantes pueden mantener la coherencia relacionando de alguna manera sus acciones con lo que se ha dicho en la conversación sin necesidad de tener que hablar sobre el tema elegido por otro participante. Por lo tanto, tener en cuenta lo que se ha dicho en la conversación y producir acciones permitidas por el contexto son condiciones esenciales para mantener la coherencia. Si cualquier acción en la conversación tiene que tener en cuenta las acciones inmediatamente anteriores para producir un efecto de total coherencia, parece lógico pensar que para asegurar la coherencia en la conversación debemos obligar a los participantes a comprobar qué se ha dicho en la conversación antes de realizar cualquier tipo de acción.

En general, en las interacciones en WhatsApp se suele mantener la coherencia en la conversación, aunque eso no implica que se hable sobre el mismo tema durante todo el intercambio. De hecho, en la mayoría de las conversaciones suele hablarse de temas diferentes, pero los saltos entre un tema y otro suelen 
producirse de manera progresiva y marcada, manteniendo así la coherencia. Por otro lado, existe la posibilidad en WhatsApp de crear grupos en los que se habla de un tema específico. En estos casos, los participantes del grupo están obligados a hablar de un tema, cosa que garantiza la coherencia.

Aunque, como hemos dicho, en general se mantiene la coherencia, la posibilidad de que se añadan múltiples hablantes a una misma conversación hace que en ocasiones encontramos conversaciones en las que distintos miembros hablan sobre un tema mientras que otros hablan de un tema diferente. Un ejemplo de conversación en el que parece que se salta de un tema a otro es el siguiente:

M- jaja judit sabe algo?

$J$ - no lo se $x D$. Le envio un sms.

$M$ - preguntale haber sino le hace gracia q vayamos jaja.

J- jajaj ok sms enviad.

$M$ - ok $x d$.

D- me han denegado la beca. Lo q me faltaba ya.

$M$ - judit ha dixo q si?

$D$ - no tengo un duro.

J- no m ha cnt aun.

$M$ - $q$ dices tiaaa! $Y$ eso??

La posibilidad de las interacciones múltiples en WhatsApp, el hecho de que sea posible que se vayan añadiendo participantes durante la conversación y que, por tanto, se yuxtapongan distintas conversaciones en la pantalla, puede tener consecuencias negativas para el mantenimiento de la coherencia. Como afirma Crystal (2002: 161), "la naturaleza no lineal de la interacción tiene todo tipo de consecuencias lingüísticas. E responde a A pero no tiene por qué haber leído a B, C, y D. Igual que E no tiene por qué estar conectado, de forma que el mensaje de E haya quedado tan relegado que pasa inadvertido".

\subsection{Dinamismo, Actividad Emergente en WhatsApp}

La conversación es un proceso dinámico y emergente. El contenido y el desarrollo de una conversación no se fijan de antemano. Los hablantes no tienen un guión que les diga qué hacer, qué decir, cómo comportarse durante el curso de la conversación. Este tipo de intercambios, por tanto, tiene una naturaleza no previsible. Los participantes en un diálogo resuelven los problemas que 
se encuentran durante la conversación utilizado guías ad hoc y teniendo en cuenta las necesidades del momento, y en ningún caso están guiados por un esquema preespecificado.

El dinamismo y la emergencia son dos características fundamentales en las interacciones en WhatsApp. En estas conversaciones no hay nada preespecificado de antemano, la conversación va tomando forma a partir de los enunciados emitidos por los participantes. Nada es previsible de antemano. Todo se calcula teniendo en cuenta el estado de la conversación en un momento dado.

\subsection{Coordinación: Protocolo de Interacción en WhatsApp}

La alternancia de turnos y los pares de adyacencia son dos importantes herramientas para garantizar la coordinación en la conversación.

\section{Alternancia de Turnos}

Decir que las conversaciones se caracterizan por la alternancia de turnos significa que durante la conversación se produce el cambio de hablante. Esto es, el participante A habla y se para; otro participante, B, empieza, habla y se para, etc. De esta manera obtenemos una secuencia A-B-A-B-A. Lo anterior es una observación a primera vista evidente. Pero si nos fijamos atentamente en este fenómeno, la manera de conseguir esta distribución es cualquier cosa excepto obvia: 1) menos de un $5 \%$ del flujo del habla es expresado en superposición; 2) y sin embargo, los intervalos entre una persona hablando y otra empezando a hablar pueden medirse frecuentemente en solo unos pocos microsegundos.

¿Cómo se logra esa transición de un hablante? Sea cual sea el mecanismo responsable, debe ser capaz de operar en circunstancias totalmente diferentes (Levinson 1983: 283):

1. El número de interlocutores puede variar de dos a veinte o más.

2. Pueden entrar y salir personas del grupo de participantes.

3. Los turnos al hablar pueden variar desde enunciados mínimos a muchos minutos de charla continua.

4. Y si hay más de dos partes entonces se prevé que todas ellas puedan hablar sin que haya un orden específico o 'cola' de hablantes. 
5. Además, parece que el mismo sistema funciona igualmente bien tanto en la interacción cara a cara como en la ausencia de control visual.

Sacks, Schegloff y Jefferson (1974) sugieren que el mecanismo que gobierna la alternancia de turnos es un conjunto de reglas que opera según una base turno por turno y que puede denominarse sistema de dirección local.

El sistema de dirección local propuesto por Sacks, Schegloff y Jefferson (1974) está estructurado en dos componentes y un conjunto de reglas:

\section{- Componentes}

1. Componente estructurador de turno (Turn-constructional component). Existen varias unidades que los hablantes pueden usar para construir un turno de habla (oraciones, sintagmas, palabras...). Al hablante se le asigna inicialmente una de esas unidades estructuradoras de turno. El final de tal unidad constituye un punto en el que los hablantes pueden intercambiarse y se denomina lugar pertinente de transición (LPT). Las reglas que gobiernan la transición de hablantes entran entonces en juego, lo que no significa que los hablantes cambiarán en ese punto sino simplemente que pueden hacerlo.

2. Componente de asignación de turno (Turn-Allocation Component). Las técnicas de asignación de turno se distribuyen en dos grupos:

a) aquellas en las que el siguiente turno es asignado por el hablante actual que selecciona al siguiente;

b) aquellas en las que el siguiente turno es asignado por auto-selección.

- Conjunto de Reglas. Se distinguen dos reglas:

1. Regla 1: Se aplica inicialmente en el primer lugar pertinente de transición de cualquier turno:

a) Si A selecciona a $\mathrm{S}$ durante el turno actual, entonces $\mathrm{A}$ debe dejar de hablar y $\mathrm{S}$ debe hablar a continuación; la transición entre uno y otro tiene lugar en el primer LPT después de la selección de $\mathrm{S}$.

b) Si A no selecciona a $\mathrm{S}$, entonces cualquier parte puede autoseleccionarse; el primer hablante adquiere los derechos para el turno siguiente.

c) Si A no ha seleccionado a $\mathrm{S}$ y ninguna otra parte se autoselecciona según la opción (b), entonces A puede (pero no es necesario) continuar.

2. Regla 2: Se aplica en todos los LPT subsiguientes: 
a) Cuando la regla 1c ha sido aplicada entonces en el siguiente LPT se aplican las reglas 1 (a)-(c), y recursivamente en el siguiente LPT hasta que se efectúa un cambio de hablante.

Las conversaciones presentan una estructura según la cual solo un participante habla cada vez. El turno de palabra es la unidad fundamental para construir una conversación. No se trata de una unidad lingüística, sino que es el hueco conversacional, en el que se encuentran las unidades constructivas de turno que pueden ser verbales o kinésicas, y pueden combinar o no signos paralingüísticos. En una unidad de turno puede haber uno o varios enunciados. Un turno de palabra estará completo cuando el hablante llegue de una manera evidente para su interlocutor a un lugar pertinente de transición. Los interlocutores reconocen estos lugares porque identifican fenómenos como los siguientes (Portolés 2004: 76):

1. Un tonema descendente en enunciados declarativos, un tonema descendente en los imperativos o la curva melódica propia de las interrogativas, descendente en las interrogativas parciales y ascendente para las totales.

2. La completitud de la construcción gramatical.

3. El alargamiento de ciertas sílabas.

4. La velocidad rápida de la emisión.

5. Finales redundantes, con un breve resumen o repeticiones de parte del último enunciado.

6. Marcadores de control del tipo ¿no?, ¿eh?, ¿verdad? o locuciones como 'o una cosa así', 'y eso' , 'ya sabes', etc.

7. Una dirección de la mirada.

El sistema de dirección local actúa de manera que los cambios de turno se producen de manera ordenada sin lapsos y sin solapamientos. En general, el oyente suele esperar a que exista un lugar pertinente de transición y después de un brevísimo intervalo de tiempo (apenas perceptible) toma la palabra. A pesar de este funcionamiento casi perfecto, suele ocurrir que los participantes no dejen que se produzca ese silencio y que, por tanto, durante un breve lapso de tiempo los participantes en la conversación hablen al mismo tiempo. Cuando esto se produce, hablamos de solapamiento. En Portolés (2004: 79-80), se distinguen tres tipos de solapamientos:

1. Superposiciones: se trata de "solapamientos de corta duración que son se perciben como violación de las reglas de alternancia de turno, se puede 
tratar de un pequeño error en la sincronización de los dos participantes o de una breve intervención que solo intenta apoyar lo que dice el primer hablante y con la que no se pretende quitar la palabra" (Portolés 2004: 79).

2. Interrupciones: se produce "cuando el interlocutor toma la palabra sin que el primer hablante haya terminado su intervención con el fin de arrebatarle el turno" (Portolés 2004: 79).

3. Intrusiones: se trata de casos en los "que toma la palabra un participante que no ha sido seleccionado por el interlocutor. [...] Existen, al menos, dos posibilidades: el hablante selecciona a un interlocutor en concreto, pero toma la palabra otro; o el hablante no selecciona a nadie en particular, pero toma la palabra un excluido" (Portolés 2004: 80).

En general, no hay problemas para la alternancia de turnos en las interacciones en WhatsApp. Se suele aplicar la misma mecánica que las interacciones cara a cara. La completitud de los enunciados producidos, los signos de puntuación, los marcadores de control del tipo ¿no?, ¿eh?, ¿verdad? y los emoticonos suelen marcar sin problemas los lugares pertinentes de transición. El hecho de que la información esté dividida en párrafos produce, en ocasiones, problemas en la alternancia de turnos, pero, en general, los usuarios cuentan con fórmulas para indicar a sus interlocutores que su turno aún no ha terminado, evitando así las interrupciones. De hecho, uno de los recursos más prácticos a este respecto lo ofrece la tecnología WhatsApp a través de la posibilidad de indicar que el emisor está "escribiendo...".

En lo referente al componente de asignación de turno, no es muy habitual encontrar conversaciones en WhatsApp en las que el hablante asigne el turno a otro participante. A veces esto puede producirse de forma indirecta, es decir, en una conversación múltiple un miembro A empieza el turno haciendo referencia a $\mathrm{B}$ y $\mathrm{C}$, esto hace que indirectamente se esté requiriendo la respuesta de esos interlocutores en concreto. Lo normal, por tanto, es que los turnos sean asignados por autoselección.

Los solapamientos no son frecuentes en WhatsApp. No obstante es posible encontrar casos de solapamientos de los distintos tipos enumerados por Portolés (2004). En general, como afirma Crystal (2002: 46), "el número de solapamientos aumenta con los participantes en el habla". Es decir, es más fácil que se produzcan solapamientos en las conversaciones múltiples que en aquellas que tienen lugar entre dos participantes. 
A veces se producen superposiciones. Los problemas en la red pueden causar estas superposiciones. En todo caso, encontramos también casos en los que sin problema alguno, el receptor se adelanta al lugar pertinente de transición causando solapamiento:

D- habeis visto el correo?

LL- sisi.

D- $d$ camp? Flipaaa.

LL-he flipado tia.

En algunas ocasiones se producen interrupciones e intrusiones. En este caso se trata de solapamientos evitables, ya que WhatsApp dispone de un mecanismo que nos indica que la otra persona está escribiendo, por lo tanto el participante puede decidir intervenir con su mensaje o bien esperar a que el otro deja de escribir y luego contestar. A continuación, ofrecemos ejemplos de estos dos tipos de solapamientos:

$R-m$ piro a descnctar.

$C$ - $n$ t e exo na pa q estes asi cnmgo.

$R-m$ vy.

$R$-disfruta $d$ tus amgos.

$C$ - yo tb ncesito $q \mathrm{~m}$ dmuestres.

$R$ - AMIGOS...

$R$-tsss

C- $q$ hblas si sl salgo pa ir a tomar alg.

$R$ - dw m piro a desconectar

LL- Marina.

LL- tng todas las fotos d peque en Tortosa.

$D$ - ee cmo q solo marina? xq $m$ excluyes.

$M-o k i$.

LL- noo q pensba q slo lo llevaba ella ajaja.

No es extraño encontrar en conversaciones múltiples intrusiones de participantes que no han sido llamados a su turno. Como indica Yus (2001), es precisamente en las interacciones múltiples donde se muestran de manera más clara las yuxtaposiciones e interrupciones de la conversación. 
Los análisis realizados nos permiten concluir que, como en la conversación cara a cara, en las interacciones en WhatsApp se producen solapamientos. En este punto diferimos de autores como Patterson (1996), Werry (1996) y Wilking (1991) que afirman: "En los turnos de habla virtual no se dan las interrupciones, solapamientos de enunciados, peticiones de protagonismo conversacional, etc., que se encuentran en una conversación cara a cara". Compartimos, en cambio, la opinión de Yus (2001), Murray (1991) y Crystal (2002) que defienden la existencia de este tipo de superposiciones en las conversaciones virtuales.

\section{Pares de Adyacencia}

Es muy habitual encontrar, en la conversación, pares de acciones. El estudio de esas estructuras ha sido llevado a cabo principalmente por Schegloff y Sacks (1973), quienes proponen el concepto de par de adyacencia para dar cuenta de las propiedades estructurales que presentan esos pares de acción. Se trata de un tipo de organización de dirección local en conversación. Los pares de adyacencia son ese tipo de enunciados pareados cuyos ejemplos prototípicos son: pregunta-respuesta; saludo-saludo, oferta-aceptación, disculpa-minimización, etc.

Frente a la alternancia de turnos, los pares de adyacencia no seleccionan al hablante, sino que seleccionan la acción. De hecho, pueden seleccionar la acción sin necesidad de seleccionar al hablante. Buena prueba de ello es que los pares de adyacencia se usan en conversaciones en las que intervienen solo dos participantes y donde no es necesario seleccionar al hablante siguiente.

La amplia presencia de estas estructuras pareadas en la conversación, independientemente de cuáles sean las circunstancias (tema, número de participantes...), ha hecho que muchos autores se dediquen al estudio de esas secuencias y sugieran nociones similares a la propuesta inicialmente. Clark (1996) propone action-response pairs; Levinson (1983) habla de preference organization; Bunt (1994) sugiere reactive pressures; discourse expectations es la noción propuesta por Reichman (1995); Allwood (1994) introduce la noción de dialogue obligations. Todas estas nociones tratan de captar el mismo hecho: cómo la producción de una determinada expresión condiciona las acciones que se pueden producir después.

Schegloff y Sacks (1973) ofrecen la siguiente caracterización de los pares de adyacencia. Los pares de adyacencia son secuencias de dos enunciados que son: 
1. Adyacentes.

2. Producidos por hablantes diferentes.

3. Organizados como una primera parte y una segunda parte.

4. Clasificados de manera que una determinada primera parte requiere una determinada segunda (o una gama de segundas partes).

La regla que gobierna el uso de los pares es la siguiente: Después de producir una primera parte de algún par, el hablante actual debe dejar de hablar y el hablante siguiente debe producir en ese punto una segunda parte del mismo par.

A la propuesta de Schegloff y Sacks (1983), Levinson (1983) plantea una serie de objeciones entre las que destacan la siguiente: la adyacencia estricta es un requisito demasiado fuerte: con frecuencia tienen lugar secuencias de inserción. No son infrecuentes numerosos niveles de inserción, con la consecuencia de que por ejemplo, entre una pregunta y su repuesta puede haber varios enunciados. El criterio de adyacencia estricta debe ser reemplazado por la noción de pertinencia condicional: dada una primera parte de un par, una segunda parte sea inmediatamente pertinente y esperable. Si no se produce esa segunda parte, su ausencia es evidente; y si en su lugar se produce otra primera parte, entonces esto se interpretará donde sea posible como un preliminar a la segunda parte, cuya pertinencia no se cancela hasta que se le presta directamente atención o hasta que fracasa a causa de un incumplimiento manifiesto en la provisión de una oración preliminar.

Los pares de adyacencia son, probablemente, la herramienta más utilizada en WhatsApp para garantizar la coordinación en la conversación. Son muy frecuentes los pares saludo-saludo, pregunta-respuesta y peticiónaceptación/rechazo que suelen ser los que organizan este tipo de interacciones. Los ejemplos siguientes ponen de manifiesto el uso de este tipo de unidades:

\author{
S- ola neni. \\ $M$ - ola guapa. \\ S- q tal? Q fas? \\ M- bn y tu? Pues na aqi haciend faena jej. \\ $S$ - preprand l cumple. \\ $C$ - cmo vas? \\ $M$ - pff haciend l primer apartado. \\ C- va trankila pokito a poko!
}




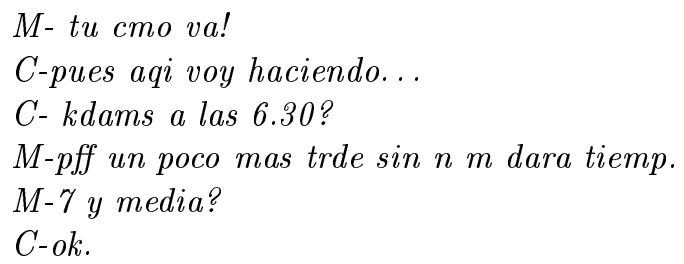

En general, se cumplen los requisitos impuestos a este tipo de secuencias. Aunque posibles, no son excesivamente frecuentes las secuencias de inserción. Las dos partes del par suelen respetar el criterio de adyacencia impuesto por Schegloff y Sacks.

\subsection{Cierres}

Los cierres en la conversación son una cuestión complicada. Los participantes en un intercambio cara a cara no pueden cerrar la conversación simplemente dejando de hablar en un momento dado. Una conversación es una actividad cooperativa. Tenemos que coordinar nuestras acciones con las de nuestros interlocutores. Y esa coordinación tiene que estar también operativa cuando intentamos cerrar la conversación.

En las interacciones en WhatsApp, los cierres se producen de la misma manera que en las conversaciones cara a cara. Como afirma Crystal (2002: 180), "las fórmulas de saludo y despedida en la conversación cara a cara se dan también en estas interacciones. Además al despedirse suele aducirse un motivo". En general, el cierre está precedido por una secuencia de precierre en la que el participante suele justificar su salida de la conversación. Estas secuencias de precierre evitan malas interpretaciones y faltas de cortesía:

S- aver cnd qdms!

$M$ - si cnd acabe todo ya hblms y qdms tranqilmn.

S-okii jeje.

$M$ - bno neni hblms q tng q ir a currar.

S- oki. M- mua guapa un bso.

S- aioo muaa (icono).

En las conversaciones múltiples también se producen estos pares de cierre. En estas interacciones, lo normal es que cuando un miembro quiere abandonar ofrece una justificación que evita los malos entendidos o simplemente la descortesía. 
Pocos son los casos en los que encontramos cierres sin secuencias de precierre. Cuando esto se produce, es decir, en aquellos casos en los que se deja de intervenir en una conversación sin fase de precierre, sin justificación del abandono, el usuario suele interpretar que su interlocutor está enfadado y que no quiere seguir hablando.

El análisis realizado en este apartado nos permite concluir que las interacciones en WhatsApp pueden ser claramente calificadas de conversacionales. WhatsApp ofrece al usuario la posibilidad de la interacción conversacional con independencia de su ubicación física. Se trata de un intercambio sincrónico de información en tiempo real.

\section{Comunicación No Verbal}

Poyatos (1994) habla de la "triple estructura básica de la comunicación" que incluye lenguaje, paralenguaje y kinésica. Estos dos últimos componentes forman parte de la llamada comunicación no verbal que representa un elemento fundamental para la interpretación de los enunciados producidos en nuestras interacciones comunicativas. En todas las formas de comunicación textual mediadas por ordenador -entre ellas el WhatsApp-, los elementos que constituyen la comunicación no verbal estarían en principio, y por definición, no presentes. Esta ausencia de comunicación no verbal podría interpretarse como una pérdida importante para la comunicación, ya que se priva a los interlocutores de una fuente primordial de datos e información. Para compensar la ausencia de los elementos no-verbales en la comunicación mediada por ordenador, los usuarios de este tipo de lenguaje han desarrollado una serie de estrategias entre las que se encuentran: 1) el uso de emoticonos que compensarían la ausencia del contacto visual y permitirán hablar de kinésica en la conversación mediada por ordenador: y 2) la frecuente transcripción de onomatopeyas e interjecciones que suplirían la ausencia de parte de los elementos que se incluyen dentro del llamado paralenguaje.

En este apartado analizaremos estas estrategias de comunicación no verbal en las interacciones en WhatsApp. Para ello, dividiremos el apartado en dos partes. En la primera definiremos qué se entiende por paralenguaje según la teoría de Poyatos (1994) y describiremos las estrategias utilizadas en WhatsApp para suplir la carencia de este elemento fundamental en las interacciones escritas. En la segunda parte, definiremos kinésica y realizaremos un breve análisis de los emoticonos. 


\subsection{Paralenguaje}

El paralenguaje se define como:

Las cualidades no verbales de la voz y sus modificadores y las emisiones independientes cuasi léxicas, producidas o condicionadas en las zonas comprendidas en las cavidades supraglóticas, las cavidad laríngea y las cavidades infraglóticas hasta los músculos abdominales, así como los silencios momentáneos, que utilizamos consciente o inconscientemente para apoyar o contradecir los signos verbales, kinésicos, proxémicos, químicos, dérmicos y térmicos, simultáneamente o alternando con ellos, tanto en la interacción como en la no interacción (Poyatos 1994: vol. II, 28).

A partir de esta definición de paralenguaje. Poyatos (1994: vol. II, 25-184) establece la siguiente clasificación de de elementos que se incluyen dentro del paralenguaje:

\section{Elementos No segmentales:}

a) Cualidades primarias. Son las que "individualizan a la persona y las más próximas a los elementos suprasegmentales de la estructura lingüística" (Poyatos 1994: vol. I, 137). Se trata de las características de la voz humana que nos diferencian como individuos. Incluyen: timbre, resonancia, intensidad, tempo, tono, campo entonativo, duración silábica y ritmo. Están condicionadas por factores biológicos, fisiológicos, psicológicos, socioculturales y ocupacionales.

b) Calificadores. Según Poyatos, "pueden ser también cualidades básicas, pero generalmente constituyen distintos tipos de voz: control respiratorio (espirado o ingresivo), control laríngeo (voz susurrante, áspera, estridente, ronca, etc.), control esofágico (voz esofágica), control faríngeo (voz hueca, apagada, etc.), control velofaríngeo (voz gimoteante, gruñona, etc.), control lingual (voz retrofleja, velarizada, etc.), control labial (por distensión o contracción de los labios), control mandibular (voz mascullante con la mandíbula cerrada y girando), control articulatorio (voz ultracorrecta, confusa, etc.), control de tensión articulatoria (voz tensa-relajada) y control objetual (hablando y comiendo a la vez, o con una pipa en la boca)" (Poyatos 1994: vol. I., 137-138). 
c) Diferenciadores: "Modifican cualitativamente las palabras y sus rasgos suprasegmentales, pero pueden también ocurrir independientemente como reacciones fisiológicas o emocionales". (Poyatos 1994: vol. I., 138). Se incluye aquí la risa, el llanto, el grito, el suspiro, el jadeo, el bostezo, la tos, el carraspeo, el escupir, el eructo, el hipo y el estornudo.

\section{Elementos Segmentales:}

a) Alternantes: "son cuasipalabras, identificables y clasificables fonética y funcionalmente y utilizados tan semánticamente como las palabras, pero la mayoría de los cuales necesitan nombres y verbos para designarlos, así como representación gráfica: clics, siseos, bisbiseos, gruñidos, imitaciones de sonidos, llamadas a animales, etc." (Poyatos 1994: vol. I., 138). Pueden ser: consonánticos, vocálicos o silencios.

En general, los usuarios de WhatsApp tienen importantes limitaciones para reproducir en el lenguaje escrito las distintas categorías paralingüísticas señaladas por Poyatos (1994).

Las cualidades primarias y los diferenciadores son en la mayoría de los casos imposibles, o muy difíciles de representar a través de las convenciones gráficas. Lo único posible en estos casos es utilizar algunas aproximaciones textuales que pueden reflejar la pronunciación del usuario de acuerdo con su origen geográfico o social. En el caso de los diferenciadores, el problema fundamental consiste en la imposibilidad de superponer los elementos paralingüísticos al texto escrito.

En lo referente a los calificadores la dificultad es parecida a los dos casos anteriores, no obstante se han propuesto algunas estrategias para reflejar estos elementos paralingüísticos en la expresión escrita como, por ejemplo, la rotulación del texto en mayúsculas para indicar voz alta.

A diferencia de lo que ocurre con las categorías anteriores, los alternantes pueden aparecer con claridad en el discurso escrito. El que no se superpongan al lenguaje verbal facilita su inserción en el texto. Es muy frecuente que los usuarios de WhatsApp introduzcan elementos de este tipo para poner de manifiesto determinados estados de ánimo o sensaciones (risa, dolor, asco, etc.).

Según Poyatos (1994: vol. II, 145), los alternantes cumplen las siguientes funciones: 
1. Expresar emociones y sentimientos voluntaria o involuntariamente: un colérico '¡Mm!', un clic 'Tz' de conmiseración.

2. Regular el mecanismo de la conversación: una ingresión faríngea para solicitar la palabra, la retroalimentación por medio de 'Ajá", 'Mm'.

3. Expresar lo que podríamos o no verbalmente, como cuando nos referimos a sonidos que a veces no sabemos describir, como '¡Plaf!', 'Glu, glu, glu'.

4. Referirse a cualidades personales: un sonido fuertemente glotalizado con los labios cerrados para denotar valor o voluntad férrea.

5. Referirse a actividades, como 'Fffp!' para representar acústicamente la rapidez de algo.

6. Referirse a conceptos abstractos: una fricción faríngea sonora fuerte y glotalizada para simbolizar la belleza inefable de un paisaje.

7. Interaccionar con los animales, llamándolos, imitando sus propias llamadas o gritos.

Idénticas funciones podemos identificar en las interacciones en WhatsApp cuando se utilizan estrategias para reproducir este tipo de elementos en el texto escrito.

Según Poyatos (1994: vol. II, 146), los alternantes pueden ser de tres tipos diferentes según relación que se establezca entre el signo y el significado:

1. Arbitrarios, sin parecido alguno con el significante ( $\mathrm{Tz}, \mathrm{Hm}, \mathrm{Mm}$ )

2. Icónicos, en los que el significante se asemeja al significado ('Bang', para un portazo, 'Pssss' para un pinchazo, ¡Be-e-e! para un cordero).

3. Intrínsecos, si el signo no imita, sino que es su propio significante con cualidades sonoras tan parecidas que, en términos, semióticos, producimos el 'modelo' y no simplemente una 'réplica'.

Teniendo en cuenta esta clasificación, la Tabla 2 recoge algunos de los alternantes más frecuentes en las interacciones en WhatsApp.

A continuación ofrecemos algunos ejemplos de uso de estos alternantes en las conversaciones en WhatsApp analizadas:

M- uii q suspiro...

A-pareces una oveja tia siempre con el beeee jaja.

A-sguro q acabas tia jummss vaya asco!

M- mmm nse q canción vy a hacer. 


\begin{tabular}{|c|c|c|c|c|c|}
\hline \multicolumn{2}{|c|}{ Arbitrarios } & \multicolumn{2}{|c|}{ Icónicos } & \multicolumn{2}{|c|}{ Intrínsecos } \\
\hline Alternante & Significado & Alternante & Significado & Alternante & Significado \\
\hline $\mathrm{Mm}$ & Dudar & Oing oing & Cerdo & Aii & Grito \\
\hline Brrr & Tiritar & Ejem ejem & Carraspeo & Buuuufff & Resoplo \\
\hline $\mathrm{Hmm}$ & Asentir & Tic tac & Reloj & Xiuuu xiuu & Silbido \\
\hline Snif snif & Llanto & Pum & Tirotear & & \\
\hline Plaf & Objeto caído & Bum & Explosión & & \\
\hline Fttp/fiu & Rapidez & Beee & Oveja & & \\
\hline Jums & Tristeza & liii & Caballo & & \\
\hline ZzZZ & Dormir & Auu & Aullar & & \\
\hline Ñam ñam & Comer & Jajaja & Risa & & \\
\hline Zas & Ostia & Ahh & Suspiro/bostezo & & \\
\hline shh & Silencio & Crac & Romperse & & \\
\hline Brrr & Tiritar & Hiip & Hipo & & \\
\hline Ajá & Asentir & Achis & Estornudo & & \\
\hline Buuh & Asustar & Grrr & Gruñido & & \\
\hline Glu glu & Beber & Argh & Enfadarse/asco & & \\
\hline Aja & Asentir & & & & \\
\hline
\end{tabular}

Table 2. Alternantes en WhatsApp.

F-tss mirala ella.

C- bufff no puedo más.

$M$ - aiii se $m$ ha olvidao!

\subsection{Kinésica}

La kinésica se define como:

Los movimientos y posiciones de base psicomuscular conscientes o inconscientes, aprendidos o somatogénicos, de percepción visual, audiovisual y táctil o cinestésica que, aislados o combinados con la estructura lingüística y paralingüística y con otros sistemas somáticos y objetuales, poseen valor comunicativo intencionado o no. Todo movimiento externo y toda posición que puedan observarse según esta definición entran dentro de la kinésica (un gesto, un respingo, un tic), ya que, desde un punto de vista cinético, no hay diferencia entre enarcar una ceja y levantar la mirada o entre una sonrisa voluntaria y la costumbre de tocarse el nudo de la corbata, puesto que todos contribuyen a la imagen visual de la persona; y en cuanto a las posturas 
que alternan o concurren con los movimientos (Ej. la postura al andar), también son kinésica por estar coestructurados con ellos (Poyatos 1994: vol. I., 137-138).

En kinésica se distingue entre:

1. Gestos: son "movimientos conscientes o inconscientes principalmente con la cabeza, la cara solo o las extremidades, dependientes o independientes del lenguaje verbal-paralingüístico, alternando con él o simultáneamente y que constituyen la forma principal de la comunicación: sonrisas, guiños..." (Poyatos 1994: vol. II, 201).

2. Maneras: "como más o menos conscientes y más o menos dinámicas, principalmente aprendidas y ritualizadas socialmente según el contexto situacional, alternando también con las palabras o simultáneas a ellas: la manera de llevarse la comida a la boca y de masticar, de toser con gesto facial y manual asociados..." (Poyatos 1994: vol. II, 201).

3. Posturas "como estáticas e igualmente conscientes o inconscientes, también ritualizadas y, como en el caso de las maneras, menos utilizadas como formas de un repertorio comunicativo, aunque, a semejanza de gestos y maneras, comunican de todas formales el sexo, la posición social, el origen cultural, el estado de ánimo, etc." (Poyatos 1994: vol. II, 201).

Se distingue dentro de las tres categorías entre:

1. Libre: "por libre debe entenderse cualquier acto cinético o posición realizado por una o más partes del cuerpo o extremidades en el espacio, es decir, por sí mismas, sin tocar otras partes del cuerpo ni ayudarse de ningún recurso objetual" (Poyatos 1994: vol. II, 202).

2. Trabado: "por trabado debe entenderse cualquier movimiento o posición en que las manos se tocan mutuamente o hacen contacto con otras partes del cuerpo, o en que cualquier parte del cuerpo hace contacto con otro cuerpo o, sobre todo, con objetos." (Poyatos 1994: vol. II, 202).

Según Yus (2001: 127), las "estrategias más utilizadas para compensar la ausencia de información visual son el emoticono y la acotación icónica". El emoticono (del inglés emoticon formado a partir de emotive e icon) es un signo icónico que representa diferentes expresiones de la cara. Por acotación icónica se entiende un texto que describe conductas no verbales. En este apartado nos vamos a centrar en el análisis de los emoticonos. 
Como indican Moral y García (2003), en la comunicación mediada por ordenador el uso de los emoticonos tiene una intención clara: la de expresar el estado anímico o emocional de los participantes en un determinado momento de la interacción. Aunque la función principal de los emoticonos es, en efecto, poner de manifiesto la emoción del hablante, es importante recordar que en ocasiones el emoticono puede modificar netamente el contenido de lo expresado:

Aunque la función del emoticono es principalmente redundante, algunas veces, sin embargo, éste pude servir para contradecir el significado del texto verbal y, en estas ocasiones, realizan el mismo papel que, por ejemplo, la gesticulación de la cara para invalidar el significado (pragmático) del enunciado oral que se está emitiendo en ese momento. [...] El emoticono puede suavizar el significado del texto electrónico e incluso otorgarle un significado opuesto (Yus 2001: 131).

De la clasificación ofrecida por Poyatos, los emoticonos utilizados en WhatsApp son fundamentalmente gestos. No obstante, podemos identificar una serie de maneras entendidas como conductas, maneras de comportarse aprendidas y ritualizadas socialmente. La tabla 3 recoge algunos de estos elementos.

\begin{tabular}{|l|c|}
\hline MANERA & SIGNIFICADO \\
\hline $\mathbf{S}$ & Saludar \\
\hline & Silenciar \\
\hline & Simbolo de la paz o manera de expresar "victoria" \\
\hline
\end{tabular}

Table 3. Maneras en WhatsApp. 
En los emoticonos, como hemos dicho, identificamos casi siempre gestos, entendidos como movimientos conscientes o inconscientes principalmente con la cabeza, la cara o las extremidades. La mayor parte de los emoticonos pueden ser clasificados como gestos libres. La Tabla 4 presenta algunos de los emoticonos más utilizados.

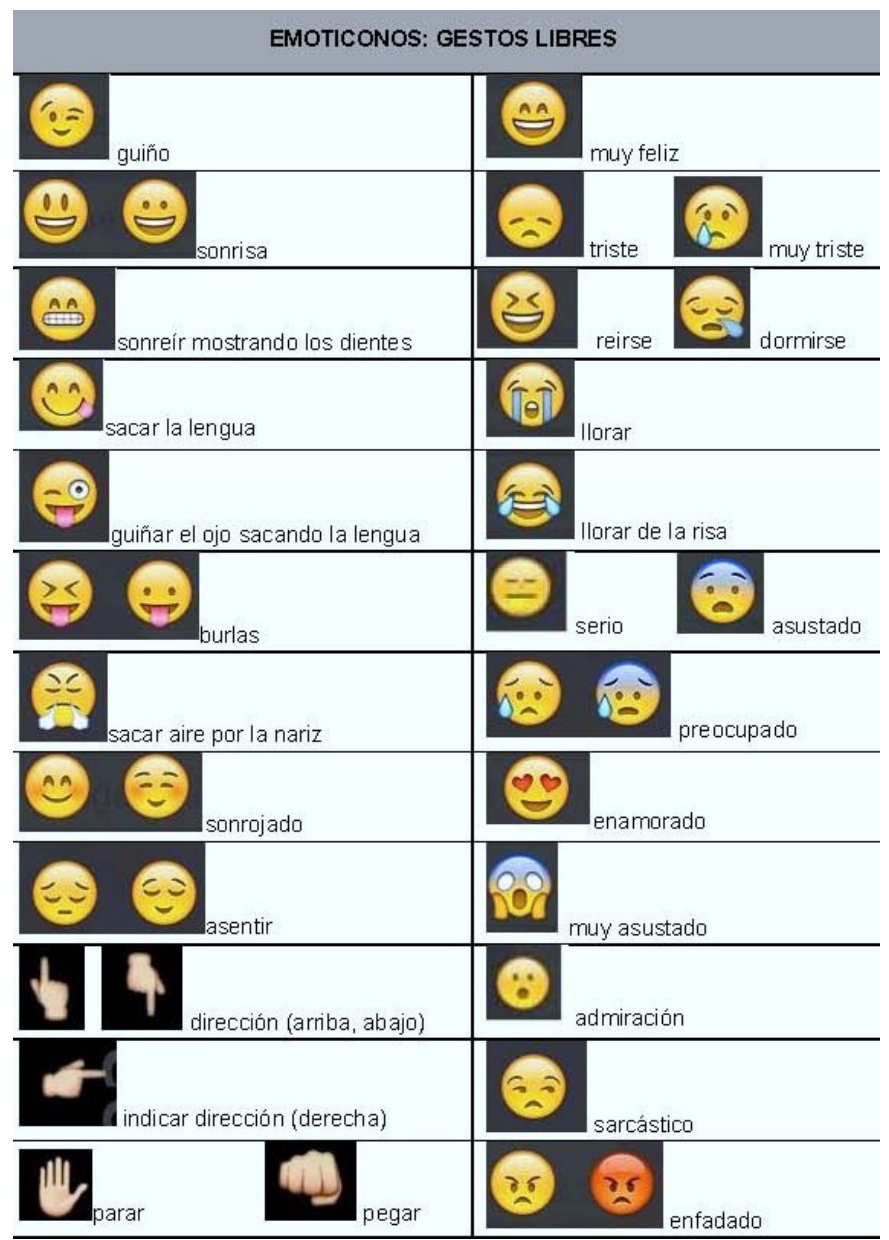

Table 4. Emoticonos más utilizados en WhatsApp. 
Entre los emoticonos que podemos clasificar como gestos trabados se encuentran los representados en la Figura 2:
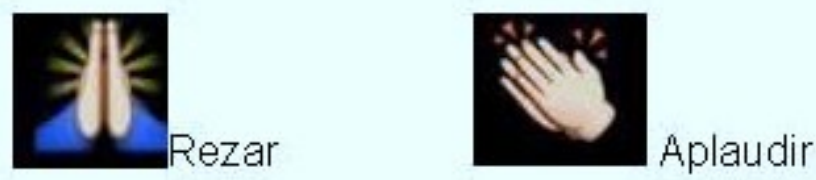

Fig. 2. Gestos trabados en WhatsApp.

Como señala Yus (2001: 123), un aspecto importante a destacar en el uso de los emoticonos como sustitutos de los gestos en las conversaciones es que "la información no verbal aportada por los usuarios no se superpone a los enunciados verbales, como ocurre en la interacción cara a cara, sino que se comunica en la sucesividad de la lengua escrita."

Junto a los emoticonos, encontramos los llamados smileys que son formas que se construyen exclusivamente con los símbolos disponibles en el teclado del teléfono. Se trata de pictogramas que combinan letras y símbolos para representar de manera muy esquemática gestos faciales. La Tabla 5 recoge algunos de los smileys más usados en WhatsApp.

Como hemos visto en este apartado, las interacciones en WhatsApp disponen de una serie de recursos (onomatopeyas, interjecciones, emoticonos) que permiten emular la entonación, el volumen, los gestos de la cara, los movimientos de las manos, las posturas, etc., en definitiva el paralenguaje y la kinésica presentes en todo acto de comunicación. Probablemente, las fórmulas utilizadas en estas interacciones no puedan equipararse a la riqueza de las conversaciones cara a cara, pero representan los elementos necesarios para presentar la comunicación no verbal que garantiza la total comprensión del mensaje emitido.

\section{Conclusiones}

El análisis realizado pone de manifiesto que los usuarios de WhatsApp han desarrollado una serie de estrategias lingüísticas innovadoras dando lugar a un 


\begin{tabular}{|c|c|}
\hline SMILYES & SIGNIFICADO \\
\hline ;-) ;) & Guiño \\
\hline :) 1 & Sonrisa \\
\hline$:-\mathrm{P}$ & Sacar la lengua \\
\hline$;-P$ & Guiñar el ojo sacando la lengua \\
\hline$x-P$ & Burlas \\
\hline$:-2))$ & Muy feliz \\
\hline$\Theta:-($ & Triste \\
\hline$:-(()$ & Muy triste \\
\hline$\because-($ & Llorar \\
\hline$\oplus:-1$ & Serio \\
\hline$:-1$ & Preocupado \\
\hline$:-\mathrm{O}$ & Admiración \\
\hline :-: [ ] & Sarcástico \\
\hline$-@$ & Enfadado \\
\hline $\mathrm{xD}$ & Reírse \\
\hline
\end{tabular}

Table 5. Smileys más utilizados en WhatsApp.

nuevo registro lingüístico adaptado al medio y con características que lo distinguen de otros usos del lenguaje. La Tabla 6 resume los aspectos principales en cada uno de los niveles estudiados.

El análisis de los elementos de la comunicación no-verbal en estas interacciones nos ha permitido identificar las estrategias utilizadas en WhatsApp para emular la entonación, el volumen, los gestos de la cara, los movimientos de las manos, las posturas, etc., presentes en todo acto de comunicación. El paralenguaje y la kinésica son sustituidos en estos textos por un nuevo lenguaje simbólico y gráfico -el de los emoticonos y las onomatopeyas- que cumple los requisitos necesarios poder hablar de comunicación no verbal electrónica (Moral \& García 2003).

Teniendo en cuenta las características básicas que distinguen oralidad y escritura resumidas en la Tabla 7 (Yus 2001: 101-105), los investigadores no se ponen de acuerdo a la hora de situar en uno de esos dos niveles la comunicación mediatizada por ordenador. Muchos son los lingüistas que afirman que este tipo de lenguaje es un texto escrito oralizado, ya que presenta la forma, el canal y el soporte que corresponde al lenguaje escrito, pero presenta muchas de las características presentes en el lenguaje oral. Yus (2001: 79) habla de oralidad del texto escrito y define este tipo de lenguaje como una "conversación oral en soporte escrito, una nueva forma de comunicación con sus propios códigos de funcionamiento." En la misma línea se sitúan Mayans (2000), que define este 


\begin{tabular}{|c|c|}
\hline NIVEL & CARACTERÍSTICAS PRINCIPALES \\
\hline Fonética/Ortografía & $\begin{array}{l}\text { - Ortografía fonética. Representación escrita del } \\
\text { lenguaje oral. } \\
\text { - Innovación tipográfica. Desviación de la ortografía y } \\
\text { tipografía estándar. } \\
\text { - Abundantes fenómenos de elisión, adición y } \\
\text { substitución de fonemas. }\end{array}$ \\
\hline Morfología & $\begin{array}{l}\text { - Se recurre constantemente al acortamiento y a la } \\
\text { abreviatura. } \\
\text { - Procesos de abreviación no son siempre estándar. } \\
\text { - Creatividad en las abreviaturas produciendo, en } \\
\text { ocasiones, la sensación de jeroglífico. }\end{array}$ \\
\hline Sintaxis & $\begin{array}{l}\text { - Simple y coloquial. } \\
\text { - Predominio de estructuras simples. } \\
\text { - Uso escaso de la subordinación. } \\
\text { - Elevado número de elipsis y omisiones de elementos } \\
\text { fundamentales de la estructura oracional. } \\
\text { - Alteración del orden de palabras para destacar } \\
\text { elementos dentro de la oración. } \\
\text { - Predominan las funciones expresiva, conativa y fática, } \\
\text { y por tanto, los vocativos, imperativos y las } \\
\text { interjecciones. }\end{array}$ \\
\hline Léxico & $\begin{array}{l}\text { - Frecuente uso de signos icónicos. } \\
\text { - Gran número de onomatopeyas e interjecciones. } \\
\text { - Abundan los anglicismos y los coloquialismos. }\end{array}$ \\
\hline Pragmática & $\begin{array}{l}\text { - Se cumplen las características de la conversación cara } \\
\text { a cara. } \\
\text { - Se respeta la alternancia de turnos. } \\
\text { - Frecuente uso de los pares de adyacencia. } \\
\text { - } \text { Actividad coherente, dinámica y emergente. } \\
\text { cos cierres se producen respetando las estrategias } \\
\text { conversacionales. }\end{array}$ \\
\hline $\begin{array}{c}\text { Comunicación } \\
\text { no verbal }\end{array}$ & $\begin{array}{l}\text { - El uso de emoticones compensa la ausencia del } \\
\text { contacto visual y permite hablar de kinésica en estas } \\
\text { interacciones. } \\
\text { - La frecuente transcripción de onomatopeyas e } \\
\text { interjecciones suplen la ausencia de parte de los } \\
\text { elementos que se incluyen dentro del paralenguaje. }\end{array}$ \\
\hline
\end{tabular}

Table 6. Caracterización lingüística de la las interacciones en WhatsApp.

tipo de lenguaje como el más oral de los registros escritos, y Daniel (2004), que lo denomina texto escrito oralizado.

Pano (2009: 4) recoge algunas de las etiquetas que ponen de manifiesto esa combinación de características de lo oral y lo escrito en las interacciones mediatizadas por ordenador: written conversation, face-to-face scripturality, 


\begin{tabular}{|l|l|}
\hline \multicolumn{1}{|c|}{ LENGUAJE ORAL } & \multicolumn{1}{c|}{ LENGUAJE ESCRITO } \\
\hline Copresencia física de los interlocutores & Ausencia de copresencia física \\
\hline Improvisado & Planeado \\
\hline Efímero & Estable \\
\hline Estilo informal y poco explícito & Estilo formal y muy explícito \\
\hline Estructuras simples & Estructuras complejas \\
\hline Tendencia a la elipsis & Oraciones completas sin elipsis \\
\hline Frases cortas & Oraciones más largas \\
\hline Abundancia de coordinación & Predominio de la subordinación \\
\hline Alteración orden de palabras & Orden normal de constituyentes \\
\hline Pobreza de léxico. Vocabulario concreto & Riqueza de léxico. Vocabulario abstracto \\
\hline $\begin{array}{l}\text { Abundancia de marcadores discursivos } \\
\text { que involucran al interlocutor }\end{array}$ & $\begin{array}{l}\text { Escasez de marcadores discursivos que } \\
\text { involucran al interlocutor. }\end{array}$ \\
\hline Errores aceptados & Errores no tolerados \\
\hline Retroalimentación & Ausencia de retroalimentación \\
\hline $\begin{array}{l}\text { Organización coherente pero no muy } \\
\text { cohesiva. }\end{array}$ & $\begin{array}{l}\text { Organización coherente y cohesiva del } \\
\text { discurso }\end{array}$ \\
\hline Comunicación no verbal & Ausencia de comunicación no verbal \\
\hline
\end{tabular}

Table 7. Diferencias entre oralidad y escritura según Yus (2001).

lengua oral tecleada. Todas estas denominaciones ponen de manifiesto lo que en términos de Vaqueiro es una hibridación de géneros:

En suma, con grados diferentes según los distintos géneros, Internet ha hecho algo más que transgredir los hábiles límites entre oralidad y escritura: ha dado origen a una hibridación que comparte rasgos de los dos medios (Vaqueiro 2012: 4).

Frente a estas caracterizaciones en las que se intenta ubicar este nuevo tipo de lenguaje dentro de uno de los dos niveles clásicos, se alzan ideas como la propuesta por Crystal (2002). Para este autor, nos encontramos ante un nuevo tipo de lenguaje que comparte rasgos con el lenguaje oral y el lenguaje escrito pero que, más allá de ser una simple combinación de ambos, constituye un nuevo tipo de lenguaje con características propias.

Existe una ciberhabla, una forma de lenguaje con características únicas y propias de Internet que se encuentra en muchas situaciones. (Crystal 2002: 31). 
Internet es un lenguaje nuevo, no es escritura hablada ni discurso escrito, es un cuarto medio "lenguaje que se transmite mediante ordenadores" (Crystal 2002: 273).

Cuatro tipos: lenguaje oral, lenguaje escrito, lenguaje gestual y lenguaje de ordenadores (Crystal 2002: 276).

Otros autores como Pano (2008) o Moral (2009) defienden la misma tesis de Crystal (2002). Nosotros, después de realizar nuestro análisis y de comprobar los rasgos que caracterizan al lenguaje utilizado en WhatsApp, convenimos con Crystal (2002) en que se trata de una nueva forma de lenguaje. No es ni lenguaje oral ni lenguaje escrito. Es una tercera (cuarta si consideramos el lenguaje signado) forma de usar el lenguaje. Se trata de una nueva manera de comunicarse que utiliza nuevos códigos. Por tanto, no podemos hablar de incorrecciones lingüísticas cuando un hablante acorta, abrevia o no acentúa una palabra, ya que esto es una de las características de esta nueva forma de lenguaje, de este nuevo código.

Por último, teniendo en cuenta las características que suelen atribuirse a los intercambios conversacionales cara a cara entre las que se encuentran el carácter oral, dialogal, inmediato, dinámico y cooperativo de estas interacciones, podemos concluir que la comunicación en WhatsApp puede calificarse de conversacional, ya que cumple todas las características establecidas excepto la primera: el canal no es oral sino escrito.

Muchas son las cuestiones que por limitación de espacio no han podido ser abordadas en este trabajo. El análisis realizado nos ha sugerido una serie de líneas de investigación que sería interesante abordar en un futuro. Destacamos las siguientes:

1. ¿Influirá el lenguaje utilizado en las interacciones en WhatsApp en otros usos del lenguaje? Si las lenguas las cambian los hablantes y el lenguaje se adapta a nuevas situaciones y evoluciona de acuerdo con el uso que el hablante le dé ¿Puede este nuevo tipo de lenguaje condicionar el cambio lingüístico?

2. ¿Qué actitudes pragmáticas se generan en estas interacciones? ¿Cómo se gestiona todo lo relacionado con la cortesía/descortesía? ¿Se puede ser más descortés/agresivo en estas interacciones? 
3. Desde el punto de vista sociolingüístico, ¿se pueden establecer diferencias en el lenguaje utilizado en WhatsApp que dependan del sexo, de la edad, del nivel de instrucción? ¿Son esas diferencias las mismas que se dan en el lenguaje oral/escrito o son diferentes?

4. ¿Cuál es el impacto que esta nueva manera de comunicarse puede tener en la enseñanza y el aprendizaje de las lenguas, tanto nativas como extranjeras?

Estos y muchos otros temas podrían ser abordados en investigaciones futuras con el objetivo de caracterizar de manera exhaustiva el lenguaje usado en WhatsApp y aplicaciones similares.

\section{Bibliografía}

1. Almela, R. (1999). Procedimientos de Formación de Palabras en Español. Barcelona: Ariel.

2. Álvarez, I. (2011). El ciberespañol: características del español en Internet. In Ortiz, L. (ed.), Selected proceedings of the 13th Hispanic Linguistic Symposium (pp. 33-41). Somerville: Cascadilla Proceeding Project.

3. Ávila, R. (2007). La lengua española en el ciberespacio: páginas oficiales y personales. In IV Congreso Internacional de la Lengua Española. Centro Virtual Cervantes.

4. Brown, P. \& Levinson, S. (1987). Politeness. Some Universals in Language Usage. Cambridge: Cambridge University Press.

5. Bunt, H.C. (1994). Context and Dialogue Control. Think, 3: 19-30.

6. Clark, H.H. (1996). Using Language. Cambridge: Cambridge University Press.

7. Crystal, D. (2002). El Lenguaje e Internet. Madrid: Cambridge University Press.

8. Crystal, D. (2006). Language and the Internet. Cambridge: Cambridge University Press.

9. Cortés, A. (2002). Lingüistica. Madrid: Cátedra.

10. Cortés, F. (2010). El lenguaje en Internet. La búsqueda de la lengua perfecta y el miedo a los nuevos medios. Goucher College.

11. Daniel, F. (2004). Internet Relay Chat: la presencia de la oralidad en una instancia comunicativa. Río Cuarto: Departamento de Lengua y Literatura. Facultad de Ciencias Humanas. Universidad Nacional de Río Cuarto.

12. Escandell, V. (1995). Cortesía, Fórmulas Convencionales y Estrategias Indirectas. Revista Española de Lingüistica, 25(1): 31-66.

13. Escandell, V. (1996). Introducción a la Pragmática. Barcelona: Ariel.

14. Escandell, V. (2005). La Comunicación. Madrid: Gredos. 
15. Farías, M. (2008). El ciberlecto de las salas de chateo: ¿conversación escrita o escritura conversada? Forma y función, 21: 347-360.

16. Fernández, M. \& Anula, A. (1995). Sintaxis y Cognición. Introducción al Conocimiento, el Procesamiento y los Déficits Sintácticos. Madrid: Síntesis.

17. Gil, J. (2007). Fonética para Profesores de Español: De la Teoría a la Práctica. Madrid: Arco Libros.

18. Hentschel, E. (1998). Communication on IRC. Linguistik online, 1/98.

19. Hernanz, M.I. \& Brucart, J.M. (1987). La Sintaxis. Barcelona: Crítica.

20. Hidalgo Navarro, A. (2006). Aspectos de la Entonación Española: Viejos y Nuevos enfoques. Madrid: Arco Libros.

21. Hidalgo Navarro, A. \& Quilis, M. (2004). Fonética y Fonología Españolas. Valencia: Tirant lo Blanch.

22. Hierro, J. (1989). Principios de Filosofía del Lenguaje. Madrid: Alianza.

23. Gómez Torrego, 1. (2001). La gramática en internet. In II Congreso Internacional de la Lengua Española. El Español en la Sociedad de la Información. Valladolid.

24. Iglesias, A.M. \& Ficardo, 1. (2007). Los chats como factor de cambio lingüístico en la lengua francesa. Interlingüistica, 17: 503-509.

25. Kasper, G. (1990). Linguistic Politeness: Current Research Issues. Journal of Pragmatics, 14: 193-218.

26. Laborda, X. (2004). Foros virtuales, ética lingüística y aspectos legales. Revista de Educación a Distancia, 12: 1-28.

27. Lakoff, R. (1973). The Logic of Politeness: Or Minding your p's and q's. In C. Corum et al. (eds.), Papers from the Ninth Regional Meeting of the Chicago Linguistic Society (pp. 292-305). Chicago: Chicago Linguistic Society.

28. Lang, M. (1990). Formación de Palabras en Español. Madrid: Cátedra.

29. Leech, G.N. (1983). Principles of Pragmatics. London: Longman.

30. Levinson, S.C. (1983). Pragmatics. Cambridge: Cambridge University Press. (Pragmática, Barcelona: Teide, 1989).

31. Llisterri, J. (2002). Marcas fonéticas de la oralidad en la lengua de los Chats: Elisiones y epéntesis consonánticas. Revista de Investigación Lingüistica, 2/V: 61-100.

32. Martínez, H. (2005). Construir Bien en Español. La Corrección Sintáctica. Oviedo: Ediciones Nobel.

33. Mayans, J. (2000). El lenguaje en los chats entre la diversión y la subversión. iWorld, 29: 42-50.

34. Millán, J. A. (2001). Internet y el español. Madrid: Biblioteca Fundación Retevisión Auna.

35. Moral, F. (2009). Internet como marco de comunicación e interacción social. Comunicar, 32: 231-237.

36. Moral, F. \& García, R. (2003). Un nuevo lenguaje en la red. Comunicar, 21: 133-136. 
37. Moré, J., Climent, S., Oliver, A. \& Taulé, M. (2005). Análisis de los fenómenos linguísticos de los mensajes de correo electrónico en catalán. Procesamiento del Lenguaje Natural, 35: 45-50.

38. Noguera, J.M. (2006). La oralidad del chat en estudiantes universitarios. Altertexto, 7/4: 59-76.

39. Pano, A. (2008). Dialogar en la Red. La Lengua Española en Chats, E-mails, Foros y Vlogs. Berlín: Peter Lang.

40. Pano, A. (2009). Diálogo y lengua española en contextos de comunicación mediada por ordenador. In Quaderni del CeSLiC. Occasional Papers (CeSLiC) (pp. 1-24). Bolonia: CeSLiC.

41. Pietrosemoli, L. \& Domínguez, E. (2001). El chateo: ¿oralidad o escritura? Revista de Investigación Lingüística, 2/ IV: 47-62.

42. Portolés, J. (2004). Pragmática para Hispanistas. Madrid: Síntesis.

43. Poyatos, F. (1994). La Comunicación No Verbal. Madrid: Istmo.

44. Prado, J. (2001). La competencia comunicativa en el entorno tecnológico: desafío para la enseñanza. Comunicar, 17: 21-30.

45. Reichman, R. (1985). Getting Computers to Talk Like You and Me. Discourse Context, Focus, and Semantics (An ATN Model). Cambridge: MIT Press.

46. Rocha, A.M. (2004). El lenguaje de los jóvenes en el chat. Estudios sobre las Culturas Contemporáneas, 19: 109-140.

47. Rodríguez, T. M. (2005). Manual de Sintaxis del Español. Madrid: Castalia.

48. Sacks, H., Schegloff, E.A. \& Jefferson, G. (1974). A Simplest Systematics for the Organization of Turn-Taking for Conversation. Language, 50 (4): 696-735.

49. Saussure, F. (1916). Cours de linguistique générale. París: Payot (Curso de Lingüistica General. Madrid: Alianza, 1987).

50. Schaff, A. (1966). Introducción a la Semántica. México: Fondo de Cultura Económica.

51. Schegloff, E.A. \& Sacks, H. (1973). Opening up Closings. Semiotica, 8: 289-327.

52. Sebeok, T. A. (2001). Signs: An Introduction to Semiotics. University of Toronto Press (Segni, Roma: Carocci, 2003).

53. Sotomayor, G. (2003). Las viejas lenguas en las nuevas tecnologías. Textos de la Cibersociedad, 3: 1-17.

54. Tusón, J. (1984). Lingüistica. Barcelona: Barcanova.

55. Valencia, Y. \& García, V. (2010). ¿De regreso al origen? La escritura simbólica y el lenguaje escrito en los usuarios del Messenger. Comunicar, 34: 155-162

56. Varela, S. (2005). Morfología Léxica: La Formación de Palabras. Madrid: Gredos.

57. Yus, F. (2001). Ciberpragmática. El Uso del Lenguaje en Internet. Barcelona: Ariel.

58. Yus, F. (2010). Ciberpragmática 2.0. Nuevos Usos del Lenguaje en Internet. Barcelona: Ariel. 
59. Vaqueiro, M. (2012). Ciberlenguaje juvenil en las redes sociales. Congreso iberoamericano de las Lenguas en la ecuación y en la cultura/IV. Salamanca: UNED.

\section{Biodata}

Marina Silva Alcántara se graduó en Lengua y Literatura Hispánica en la Universitat Rovira i Virgili, en la promoción 2009-2013. Su Trabajo Final de Grado fue de ámbito lingüístico. Cursó el Máster Universitario de Formación del Profesorado de Secundaria Obligatoria y Bachillerato, Formación Profesional y Enseñanza de Idiomas en la Universitat de Barcelona, en la promoción 2013-2014, para poder dedicarse a la docencia. Creó un proyecto basado en la adquisición de la competencia oral en el aula que desarrolló en el Instituto Sant Pere i Sant Pau durante las prácticas y que, posteriormente, se reflejó en el Trabajo de Fin de Máster. 